\title{
ARISTONECTES QUIRIQUINENSIS, SP. NOV., A NEW HIGHLY DERIVED ELASMOSAURID FROM THE UPPER MAASTRICHTIAN OF CENTRAL CHILE
}

\author{
RODRIGO A. OTERO, ${ }^{*}, 1$ SERGIO SOTO-ACUÑA,,${ }^{1,2}$ FRANK ROBIN O'KEEFE, ${ }^{3}$ JOSÉ P. O'GORMAN, ${ }^{4}$ \\ WOLFGANG STINNESBECK, ${ }^{5}$ MARIO E. SUÁREZ, ${ }^{1}$ DAVID RUBILAR-ROGERS, ${ }^{2}$ CHRISTIAN SALAZAR, ${ }^{2}$ \\ and LUIS ARTURO QUINZIO-SINN ${ }^{6}$ \\ ${ }^{1}$ Laboratorio de Ontogenia y Filogenia, Departamento de Biología, Facultad de Ciencias, Universidad de Chile, Las Palmeras 3425, \\ Santiago, Chile, paracrioceras@gmail.com; arcosaurio@gmail.com; \\ ${ }^{2}$ Museo Nacional de Historia Natural. Casilla 787, Santiago, Chile, drubilar@mnhn.cl; christian.salazar@mnhn.cl; \\ ${ }^{3}$ División Paleontología de Vertebrados, Museo de La Plata, Universidad Nacional de La Plata, Paseo del Bosque s/n., B1900FWA, \\ La Plata, Argentina, and CONICET, Consejo Nacional de Investigaciones Científicas y Técnicas, Argentina, \\ joseogorman@fcnym.unlp.edu.ar; \\ ${ }^{4}$ Department of Biological Sciences, Marshall University, Huntington, West Virginia 25755, U.S.A., okeefef@marshall.edu; \\ ${ }^{5}$ Institut für Geowissenschaften, Universität Heidelberg, INF 234, 69120 Heidelberg, Germany, \\ wolfgang.stinnesbeck@geow.uni-heidelberg.de; \\ ${ }^{6}$ Departamento Ciencias de la Tierra, Universidad de Concepción, 160 C Concepción, Chile, lquinzio@udec.cl
}

\begin{abstract}
This paper describes a new species of elasmosaurid plesiosaur, Aristonectes quiriquinensis, sp. nov., based on a partial skeleton recovered from upper Maastrichtian beds of the Quiriquina Formation of central Chile. The material described here consists of two skeletons, one collected near the village of Cocholgue, and a second juvenile specimen from Quiriquina Island. Prior to these finds, Aristonectes was viewed as a monospecific genus, including only the enigmatic Aristonectes parvidens, the holotype of which consists of an incomplete skull and incomplete postcranium. Other material referred to the genus includes an incomplete juvenile skull and other postcranial material from the upper Maastrichtian of Antarctica, as well as a partial skull from the Quiriquina Formation of central Chile. The relationships of Aristonectes have been controversial, with competing theories assigning the genus to Cryptoclididae, Elasmosauridae, and Aristonectidae; however, there is a developing consensus that Aristonectes is a derived elasmosaurid, and this paper gives strong evidence for this view. Comparison of the specimen here studied with the holotype of $A$. parvidens demonstrates that A. quiriquinensis is a distinct species. The completeness of the adult skeleton allows the first confident size estimates for adult Aristonectes. It is a large plesiosaurian with a relatively large skull with numerous homodont teeth, a moderately long and laterally compressed neck, and relatively narrow trunk, with slender and elongate forelimbs. The two specimens are restricted to the upper Maastrichtian of central Chile, posing questions concerning the austral circumpolar distribution of different elasmosaurids towards the end of the Cretaceous.
\end{abstract}

SUPPLEMENTAL DATA—Supplemental materials are available for this article for free at www.tandfonline.com/UJVP

\section{INTRODUCTION}

Since its first description by Cabrera (1941), Aristonectes parvidens (Sauropterygia, Plesiosauroidea), from the Maastrichtian of Argentina, was regarded as a highly unusual plesiosaurian. The holotype (MLP 40-XI-14-6) includes a fragmentary skull, the atlas-axis, several anterior cervical vertebrae (probably a continuous series), five anterior caudal centra (probably continuous), three isolated posterior caudal centra, and one incomplete limb. This plesiosaur is characterized by a large and slightly flattened skull, a mandible with a large number (60-65) of small alveoli, and cervical vertebrae reduced in length with an average vertebral length index (VLI) near 80, instead of a more typical VLI close to 140 in Elasmosaurus platyurus (O'Keefe and Hiller, 2006). Excluding the very high skull of Kaiwhekea katiki Cruickshank and Fordyce, 2002, similar features are not known to exist in other elasmosaurid taxa, explaining why the taxon was referred with doubts to the clade Elasmosauridae in its first description (Cabr-

\footnotetext{
*Corresponding author.
}

era, 1941). The taxonomic position of Aristonectes was discussed by Brown (1981), who included it within Cryptoclididae, based mostly on the presence of more than five premaxillary teeth, a character shared with Jurassic Cryptoclidus and Kimmerosaurus. Subsequently, Chatterjee and Small (1989) described 'Turneria' seymourensis from the upper Maastrichtian of Seymour Island, Antarctica, based on a fragmentary skull. The specimen was reassigned to 'Morturneria seymourensis' by Chatterjee and Creisler (1994), due to preoccupation of the genus name, and it was originally referred to Cryptoclididae. 'Morturneria seymourensis' was included in a phylogenetic analysis of the Plesiosauria by O'Keefe (2001), which grouped it within 'Cimoliasauridae.' Further discoveries in the Southern Hemisphere of 'cryptoclidoid' plesiosaurians, particularly Kaiwhekea katiki from the Maastrichtian of New Zealand (Cruickshank and Fordyce, 2002), reinforced the idea of an austral radiation of Cryptoclididae during the Late Cretaceous. This interpretation was questioned by Gasparini et al. (2003a), who redescribed the holotype of $A$. parvidens, revealing affinities with Elasmosauridae: they considered ' $M$. seymourensis' to be a junior synonym of $A$. parvidens. Following Gasparini et al. 
(2003a), cryptoclidids were thus restricted to the Jurassic of the Northern Hemisphere.

An extensive phylogenetic analysis of the Plesiosauria was carried out by Druckenmiller and Russell (2008), but A. parvidens and other plesiosaurians from the Upper Cretaceous of the Southern Hemisphere (e.g., Mauisaurus haasti Hector, 1874; Tuarangisaurus keyesi Wiffen and Moisley, 1986; and K. katiki) were excluded due to their fragmentary preservation. O'Keefe and Street (2009) reviewed the taxonomic status of $A$. parvidens, as well as the status of 'Cimoliasauridae,' concluding that this latter family is a junior synonym of Elasmosauridae (O'Keefe and Street, 2009). A. parvidens, K. katiki, Tatenectes laramiensis (O'Keefe and Wahl, 2003), and the genus Kimmerosaurus were grouped into a new family, Aristonectidae (O'Keefe and Street, 2009), within cryptocleidoid plesiosaurians. Ketchum and Benson (2010) provided a large-scale phylogenetic analysis of Plesiosauria and among other conclusions found that $K$. katiki is a derived leptocleidid and $A$. parvidens an elasmosaurid. Ketchum and Benson (2011a) modified their earlier data set, recovering new relationships for $K$. katiki and $A$. parvidens, assigning both to Elasmosauridae, supporting the previous proposal of Gasparini et al. (2003a). In addition, O'Gorman et al. (2013) developed a graphic bivariate analysis that allowed the cervical vertebrae of juvenile specimens of Aristonectes to be distinguished from those of other young elasmosaurids, particularly those from the Northern Hemisphere. At the same time, an almost complete postcranial skeleton of an elasmosaurid was described by Otero et al. (2012) from the upper Maastrichtian of Quiriquina Island, Chile, and included in a phylogenetic analysis based on the data set of O'Keefe and Street (2009), but also including other Late Cretaceous elasmosaurids from both hemispheres. The results of this analysis supported the results of Gasparini et al. (2003a) and Ketchum and Benson (2011a), placing Aristonectes and related taxa into a derived group within Elasmosauridae. This clade, considered to represent a new subfamily, Aristonectinae, includes $A$. parvidens, $K$. katiki, Futabasaurus suzukii Sato, Hasegawa, and Manabe, 2006, from the Santonian of Japan, and the new Chilean taxon described by Otero et al. (2012) and in this paper.

The systematic placement of $A$. parvidens was thus contentious for more than 70 years, although there is now a developing consensus that Aristonectes and related taxa belong within Elasmosauridae. The geographic range of this genus was extended from Argentina to most of the Weddellian Biogeographic Province (WBP; Zinsmeister, 1979), including records from the upper Maastrichtian of central Chile (Casamiquela, 1969; Suárez and Fritis, 2002; Suárez et al., 2003), Argentine Patagonia (Cabrera, 1941; Gasparini et al., 2003b; O'Gorman et al., 2013), and Antarctica (Chatterjee and Small, 1989; O'Gorman et al., 2010, 2013). In this article, we describe a new specimen of a young adult Aristonectes that provides relevant information about the postcranium, including a largely complete cervical sequence, the pectoral girdle, forelimbs, and hind limbs. The adult pectoral girdle of Aristonectes is here described for the first time, including an open cordiform fenestra, a highly diagnostic feature of the family Elasmosauridae, as originally proposed by Gasparini et al. (2003a). The new material studied here represents one of the most informative specimens of Aristonectes known to date and significantly improves our knowledge and understanding of this enigmatic genus of marine reptiles.

\section{LOCALITY AND GEOLOGIC SETTING}

The specimen documented here was discovered on the sea coast at the village of Cocholgüe $\left(36^{\circ} 35^{\prime} 40^{\prime \prime} \mathrm{S} ; 72^{\circ} 58^{\prime} 40^{\prime \prime} \mathrm{W}\right)$, a coastal hamlet located in the Biobío Region, $25 \mathrm{~km}$ north of Concepción,

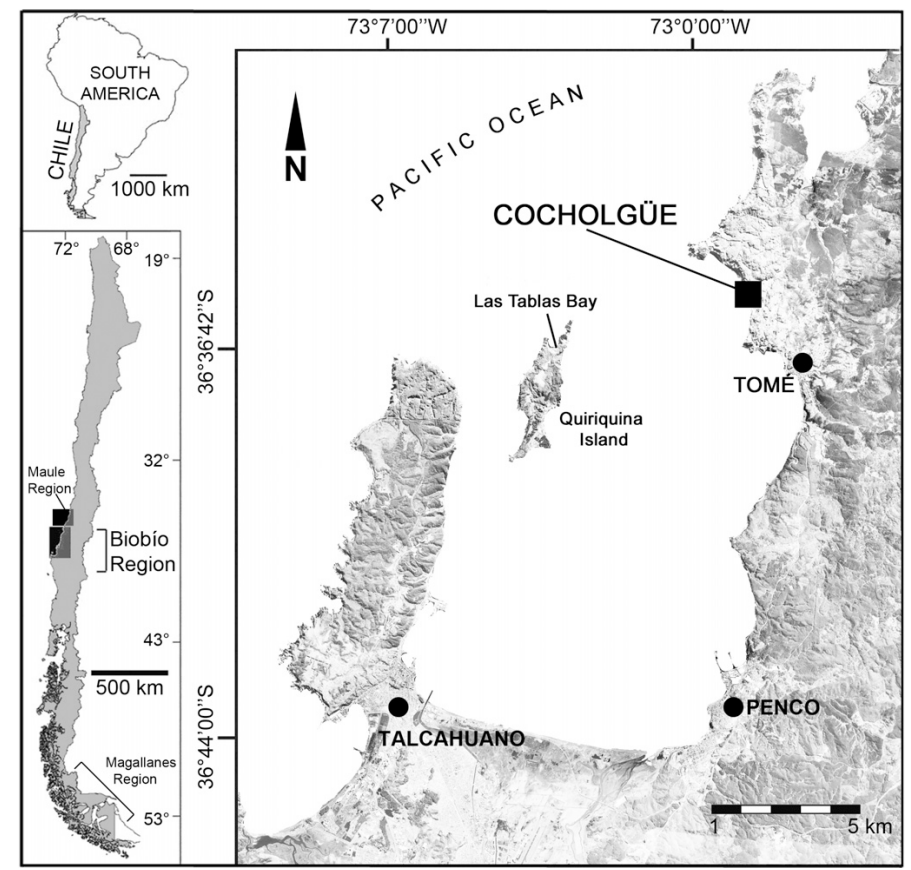

FIGURE 1. Map of the bay of Concepción, Biobío Region, central Chile indicating the location of the fossil site near Cocholgüe $\left(36^{\circ} 35^{\prime} 40^{\prime \prime} \mathrm{S}\right.$; $72^{\circ} 58^{\prime} 40^{\prime \prime} \mathrm{W}$ ), from where the holotype of Aristonectes quiriquinensis, sp. nov., was collected. The referred specimen, SGO.PV.260 was recovered from Las Tablas Bay, Quiriquina Island.

and approximately $400 \mathrm{~km}$ south of Santiago, in central Chile (Fig. 1). The sediments exposed along the coast north and south of Cocholgüe are Maastrichtian to Paleogene in age and include complete and well-exposed sections of the Quiriquina Formation (Biró-Bagóczky, 1982; Stinnesbeck, 1986). Cocholgüe was designated a paratype locality of the Quiriquina Formation by BiróBagóczky (1982). The base of this unit is formed by a fossiliferous microconglomerate and cross-bedded yellow sandstone. These sediments directly overlie a paleocliff of Paleozoic slates of the Hercynian basement that constitutes the main part of the Chilean coastal range. The basal transgressive sand and conglomerate horizon is between 1.5 and $2 \mathrm{~m}$ thick and include abundant bivalvians and less frequent gastropods. Upsection sediments gradually change in color from yellow to green. The upper levels comprise bio-turbated glauconitic sandstone and siltstone with sandy calcareous concretions that reach a thickness of $45 \mathrm{~m}$ (Fig. 2). The Quiriquina Formation was initially considered to be Campanian-Maastrichtian in age based on abundant and diverse ammonoids and bivalves (e.g., Biró-Bagóczky, 1982), but subsequent revisions of the ammonoid assemblage refined the age to Maastrichtian (Stinnesbeck, 1986) and then to upper Maastrichtian (Stinnesbeck, 1996; Salazar et al., 2010; Stinnesbeck et al., 2012). Fossil vertebrates are relatively common in the middle levels of the unit and they frequently occur in calcareous sandstone concretions; this is the case of the referred specimen SGO.PV.260. The holotype specimen was found in upper levels of the formation, around $5 \mathrm{~m}$ below the contact with the overlying Curanilahue Formation (Eocene), being the youngest occurrence of a plesiosaurian in the unit. Turtle remains of the genus Euclastes were also recovered in the upper levels of the Quiriquina Formation (Gasparini and Biró-Bagóczky, 1986). Other vertebrates are represented by cartilaginous and (less frequent) bony fishes (Suárez et al., 2003; 


\section{LAS TABLAS BAY}

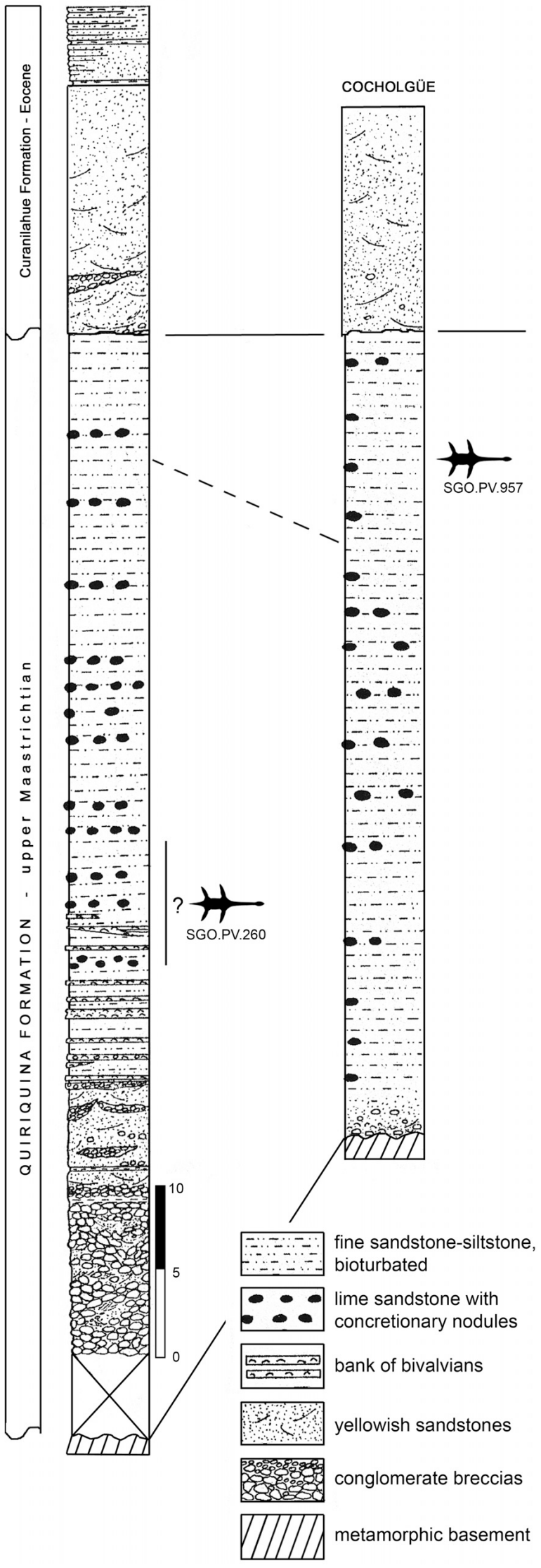

Suárez and Otero, 2009), mosasaurids (Jimenez-Huidobro et al., 2010), birds (Lambrecht, 1929; Olson, 1992), and plesiosaurians, which are the most abundant marine reptiles in the unit, having been reported since the 19th century (Gay, 1854; Philippi, 1887; Steinmann et al., 1895; Broili, 1930; Wetzel, 1930; Fuenzalida, 1956; Casamiquela, 1969; Gasparini, 1979).

\section{MATERIALS AND METHODS}

The present specimen was recovered in two excavations at the beach near Cocholgüe. In 2001, one of the authors (M.E.S.) collected a partial skull, mandibular fragments, and 12 anterior cervical vertebrae that were exposed in the intertidal zone. The anterior portion was already lost due to erosion. This material was later described by Suárez and Fritis (2002) and referred to the genus Aristonectes. Species-level identification was precluded at that time due to the lack of preparation. A second excavation was independently executed at the same site in early 2009 and was carried out by a team of the Universidad de Concepción (Chile) and the Institut für Geowissenschaften, Universität Heidelberg (Germany). This excavation recovered 119 blocks of sandstone, most of them with bony material, some damaged due to the degradation of the bones by periodic seawater immersion that turned the more delicate portions into brittle surfaces. Also, several contacts were lost because sandstone blocks were cut out of the beach with a rock saw at low tide.

The precise location of both excavations (skull in 2001 and postcranial skeleton in 2009) was identified during 2009 by two of the authors (R.A.O., D.R.R.), confirming that they were recovered from the same stratigraphic layer and separated by a distance of only $1.5 \mathrm{~m}$ (Fig. 3). The taphonomic distribution of bones was consistent in the two excavations, indicating a north-southdirected dispersal pattern of the skeleton (Fig. 3), with the skull and anterior vertebrae directed to the south and the trunk to the north. Bones recovered in each excavation are anatomically complementary, also indicating that they result from a single skeleton, and despite intensive searches on site, no other vertebrate remains were observed, further suggesting that both excavations produced material from a single individual. Finally, measurements of the cervical centra (including correlated VLI indexes sensu Brown, 1981; O'Keefe and Hiller, 2006), and taphonomic features such as a similar pattern of distortion with cervical vertebrae crushed to the right side, are also consistent with a single individual.

After concluding that the material forms part of the same skeleton, the fossil bones were transported from Concepción to Santiago in January 2010 and reunited at the Museo Nacional de Historia Natural (National Museum of Natural History) for preparation and scientific analysis. During this process, remains of marine invertebrates were recovered, including Cardium (Bucardium) acuticostatum (Bivalvia, Cardiidae) and aff. Grossouvreites sp. (Ammonoidea, Kossmaticeratidae), as well as vertebrates such as Carcharias sp. (Lamniformes, Odontaspididae) and vertebrae of indeterminate bony fishes.

The skull, cervicals, and limbs of the studied specimen were directly compared with the holotype of Aristonectes parvidens housed at the Museo de La Plata, Argentina (R.A.O., J.P.O., pers. observ.).

$\leftarrow$ FIGURE 2. General stratigraphic column of the Quiriquina Formation exposed at Las Tablas Bay, the type locality, and Cocholgüe, the paratype locality of the unit, indicating the estimated stratigraphic position of the referred specimen (left) and the holotype (right) of Aristonectes quiriquinensis, sp. nov. Taken from Stinnesbeck (1986). 
Institutional Abbreviations-CM.Zfr, Canterbury Museum, Christchurch, New Zealand; MLP, Museo de La Plata, Buenos Aires, Argentina; SGO.PV, Museo Nacional de Historia Natural, Santiago, Chile; TTU, Museum of Texas Tech University, Lubbock, Texas, U.S.A.

Anatomical Abbreviations-aa, atlas-axis complex; act, acromion tuberosity; alf, anterior left flank; an, angular; atc, atlas centrum; ati, atlas intercentrum; axa, axis arch; axc, axis centrum; axr, axis rib; az, anterior zygapophysis; bes, basioccipitalexoccipital suture; boc, basioccipital; c3, third cervical; c4, fourth cervical; ce, centrale; cf, cordiform fenestra; cp, coronoid process; cr, cervical rib; crp, crushed right parietal; d, dentary; dc1, distal carpal 1 ; dc2+3, distal carpal $2+3$; dc4, distal carpal 4; df, distal facet; dps, dorsal process of scapula; ds, dorsum sellae; dt1, distal tarsal 1; dt2+3, distal tarsal 2+3; dt4, distal tarsal 4; dv, dorsal vertebrae; ec, ectopterygoid; f, foramina; fb, fibulare; fi, fibula; fm, foramen magnum; g, gastralia; gl, glenoid; gt, great tuberosity of the humerus; h?, hyoid?; hh, humerus head; ipv, interpterygoidal vacuity; ir, intercentrum rib; lc, left coracoid; ld, left dentary; leo, left exoccipital-opisthotic; lh, left humerus; lk, lateral keel; lm?, left maxillar?; lp, left parietal; lpt, left pterygoid; ls, left scapula; Ir, left ramus of the mandible; lvp, left ventral process of the coracoid; mat, muscle attachment; mb, mental boss; mc, Meckelian canal; mc1, metacarpal 1; mc5, metacarpal 5; mg, Meckelian groove; mt1, metatarsal 1; mt5, metatarsal 5; mat, muscle attachment; nap, neural arch pedicel facet; nc, neural canal; ns, neural spine; oc, occipital condyle; om, orbit margin; paa, peduncle of the atlas arch; pal, palatine; pao, postaxial ossicle; pdp, paradental plate; pef, pectoral fossa; pf, pineal foramen; pop, paroccipital process; prf, posterior right flank; ps, parasphenoid; pvc, posterior vertical semicircular canal; pz, posterior zygapophysis; q, quadrate; r, radius; ra, radiale; rap, retroarticular process; rb, rib; rc, right coracoid; rd, right dentary; reo, right exoccipital-opisthotic; rf, right femur; rft, rib facet; rh, right humerus; rp, right parietal; rpt, right pterygoid; rs, right scapula; rvp, right ventral process; s, squamosal; sa, surangular; sar, squamosal arch; scr, sagittal crest; sd, symphysis of dentaries; soc, supraoccipital; sp, splenial; st, sella turcica; tb, tibiale; tc, tooth crown; ti, tibia; to, tooth; tr, tooth root; ul, ulna; un, ulnare; vf, ventral foramina.

\section{SYSTEMATIC PALEONTOLOGY}

DIAPSIDA Osborn, 1903

SAUROPTERYGIA Owen, 1860

PLESIOSAURIA de Blainville, 1835

ELASMOSAURIDAE Cope, 1869 (sensu Ketchum and Benson, 2010)

ARISTONECTINAE Otero, Soto-Acuña, and Rubilar-Rogers, 2012

ARISTONECTES Cabrera, 1941

Type Species-Aristonectes parvidens Cabrera, 1941. MLP 40XI-14-6 (holotype), part of a skull attached to the mandible, atlasaxis, and 21 other cervical vertebrae of which the anterior 16 are articulated, eight caudal vertebrae, and an incomplete limb. Cañadón del Loro, northwestern Chubut Province, Argentina. Paso del Sapo Formation, Lefipan Member, Maastrichtian (Gasparini et al., 2003a).

Emended Diagnosis - This diagnosis is modified from Gasparini et al. (2003a) and is restricted to the combination of characters that are common to $A$. parvidens and A. quiriquinensis, sp. nov., but absent in all other Maastrichtian aristonectine plesiosaurians: large, slightly flattened, low, and broad skull without premaxillary-maxillary constriction, differing from the high skull of Kaiwhekea katiki; gracile mandible with very short symphysis; homodont dentition with more than 50 procumbent alveoli; forelimb with high aspect ratio, and with elongated, spool-shaped phalanges having expanded articular facets. Anterior and middle cervical vertebrae with low average VLI $(\sim 80)$, but slightly high compared with Kaiwhekea katiki.

A second group of characters could be useful for differentiating Aristonectes from Kaiwhekea, although they are not known in all of the respective skulls: $10-13$ premaxillary teeth (not preserved in A. quiriquinensis, sp. nov., specimens), differing from the seven premaxillary teeth of Kaiwhekea; 50 or more teeth in the maxilla (not known in A. quiriquinensis, sp. nov.), differing from the 36 teeth recorded in Kaiwhekea. The referred specimen of $A$. quiriquinensis, sp. nov. (SGO.PV.260), confirms that the distinctive anterior caudal vertebrae are broader than high and higher than large, with an octagonal outline in articular view, as a potentially diagnostic character of the genus (O'Gorman et al., 2010). These were previously regarded as sacral vertebrae by Otero et al. (2012). Such features must be verified in Kaiwhekea.

Historical Specimens Referred to Aristonectes sp.-Various specimens have been referred to the genus Aristonectes, including Victorian material. Most of the material is isolated, although some is referable to Aristonectes.

Quiriquina Island, central Chile: Quiriquina Formation, upper Maastrichtian. A collection of material (Gay, 1847, 1848) comprising parts of several individuals based on relative centrum measurements, but the only elements diagnostic to genus are an octagonal anterior caudal centrum and the caudal centrum (Gay, 1848:pl. I, figs. 1-3 and 6-10) (O'Gorman et al., 2013). This material was referred by Steinmann et al. (1895:pl. I, fig. 8) to Pliosaurus chilensis (Gay, 1847).

Quiriquina Island, central Chile: Quiriquina Formation, upper Maastrichtian. Repository unknown. A posterior cervical centrum with bilobed articular facets and large, oval, ventral foramina, all referred to Cimoliasaurus sp. by Steinmann et al. (1895:pl. I, fig. 5).

Quiriquina Island, central Chile: Quiriquina Formation, upper Maastrichtian. Fragment of rostrum and mandible with small, procumbent alveoli (SGO.PV.82), referred to Aristonectes by Casamiquela (1969) and later referred to Aristonectes parvidens Cabrera, 1941, by Gasparini et al. (2003a:fig. 2H). Only diagnostic to genus level.

\section{ARISTONECTES QUIRIQUINENSIS, sp. nov. (Figs. 4-16)}

Holotype-SGO.PV.957. Skeleton including the skull, atlasaxis, 12 anterior cervicals, 23 middle-to-posterior cervicals, most of the trunk, both almost complete forelimbs, and most of the proximal portion of the right hind limb.

Locality-Cocholgüe, Biobío Region, central Chile.

Horizon and Age-Upper levels of the Quiriquina Formation (Biró-Bagóczky, 1982), upper Maastrichtian.

Diagnosis-A species within Aristonectes with the following unique combination of characters: head proportionally smaller than that of $A$. parvidens, having larger cervical vertebrae and the skull more reduced; presence of a mental boss on the anteroventral surface of the symphysis, which is not present in $A$. parvidens; absence of lingual platform in ventral view, which is present in $A$. parvidens (Gasparini et al., 2003a:fig. 2B); anterior portion of the mandible more dorsoventrally compressed than in $A$. parvidens (Gasparini et al., 2003a:fig. 2A); anterior teeth with sharp, slender shape (extreme expression of character 46, state 2, 'needle-like' in O'Keefe and Street, 2009); rib of the atlas-axis consisting of a large projection from the atlas intercentrum together with the axis rib, contrary to $A$. parvidens where the atlas intercentrum has only a small posterolateral process that covers the proximal part of the axis rib; ribs of first cervical vertebra shorter than those of $A$. parvidens, without fusion of their distal end with the rib of the third cervical; middle and posterior cervical vertebrae having neural spines and cervical ribs strongly angled anteriorly near $30^{\circ}$. 

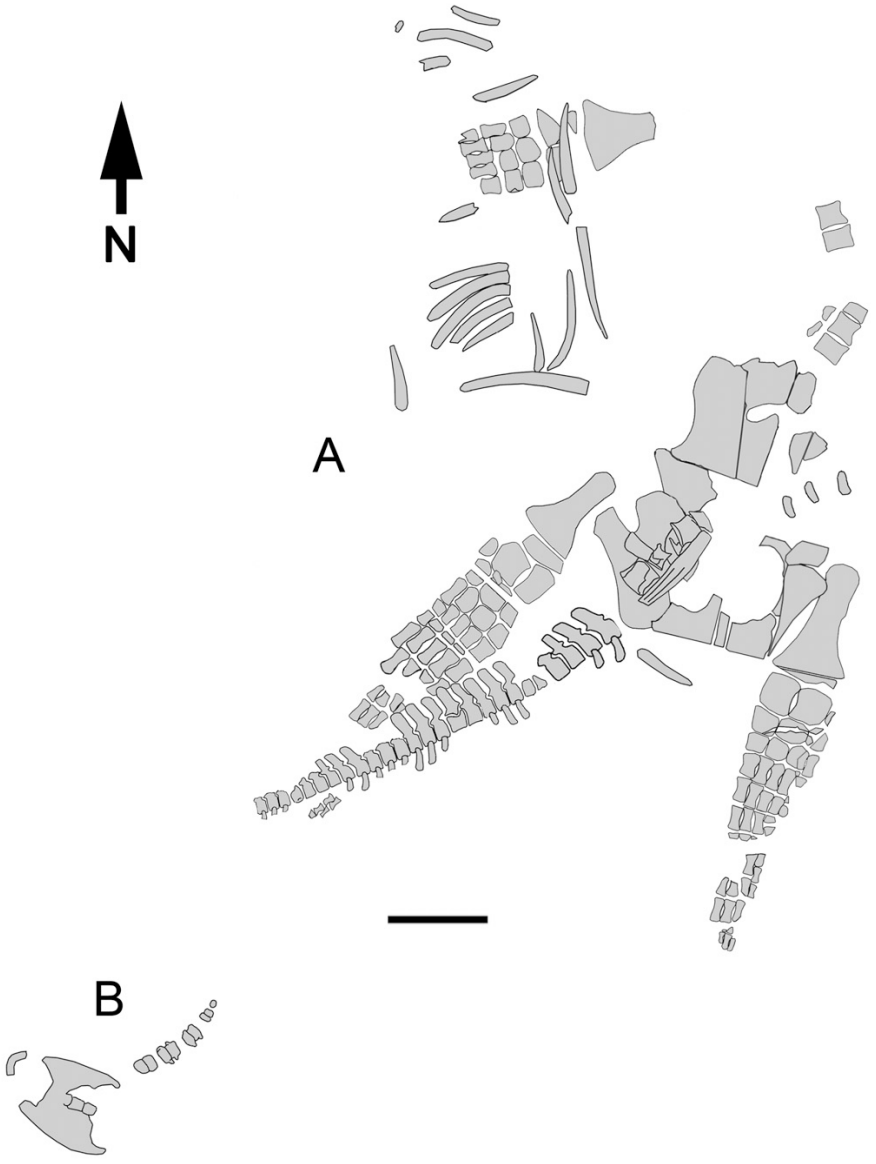

FIGURE 3. Quarry diagram showing the material recovered. A, postcranial remains recovered during 2009; B, skull and anterior cervical vertebrae recovered in 2001. Scale bar equals $500 \mathrm{~mm}$.

Due to incomplete knowledge of the anatomy of $A$. parvidens, the following features are only tentatively diagnostic for the species: neural spines of posterior cervicals with an anterior left delicate bony flange and posterior right flange; humerus with hemispherical articular head; epipodials nearly $30 \%$ longer proximodistally than broad mediolaterally; lunate radius and ulna without distinctive middle notch; broad, polygonal centrale in the forelimb, broader mediolaterally than long proximodistally; fused carpals $2+3$; forelimb with proximal phalanges spool-shaped but elongate, with expanded polygonal articular facets; scapulae having the acromion tuberosity displaced to the margin of the pectoral fenestra; coracoids with the following combination of features: high conical ventral processes not fused on the midline, whereas the dorsal surface is strongly fused; dorsal transverse process shallow, almost flat in aspect; typical elasmosaurid embayment (cordiform fenestra) between the coracoids on the posterior midline, but with midline fusion of the medial processes of the coracoids behind the cordiform fenestra.

Etymology-The specific name follows its typical geologic unit, the Quiriquina Formation, and its occurrence in the Quiriquina Basin. Pronunciation: ki-ree-ki-nensis.

Referred Specimen-SGO.PV.260. A mostly complete postcranial skeleton of a juvenile individual. Las Tablas, Quiriquina Island, Biobío Region. Quiriquina Formation, upper Maastrichtian.
Referred to Aristonectinae indet. by Otero et al. (2012) and to Aristonectes sp. by Otero and O'Gorman (2013).

Note-The specimen studied here was formerly referred to Aristonectes sp. (Suárez and Fritis, 2002; Suárez et al., 2003).

\section{ONTOGENETIC OBSERVATIONS}

The holotype of $A$. quiriquinensis possesses a partial skull, including the mandible, with an estimated length of $65-70 \mathrm{~cm}$, and the width across the quadrates is close to $40 \mathrm{~cm}$. It is thus slightly smaller than the holotype of $A$. parvidens $(73.5 \mathrm{~cm})$, interpreted as an adult and probably an old individual (Gasparini et al., 2003a), and slightly larger than the skull of $K$. katiki (Cruickshank and Fordyce, 2002). All neural arches and ribs of the cervical vertebrae are tightly fused to the centra, indicative of 'adult' growth stages (see Brown, 1981:267). Most sutures in the mandibles are visible, and the scapula, as well as the medial and anterior portions of the coracoid, is well ossified. Also, the coracoids in juvenile specimens of the genus are known to have an open cordiform fenestra (Otero et al., 2012; O'Gorman et al., 2013), whereas in the holotype of $A$. quiriquinensis it is secondarily closed, indicating a more advanced ontogenetic stage compared with the postcranial referred specimen (SGO.PV.260). In A. quiriquinensis, the ventral processes of the coracoids are separated, whereas their dorsal symphysis is completely fused. This is remarkable because an opposite condition is observed in an indeterminate elasmosaurid from the Maastrichtian of New Zealand in which the dorsal surface of the coracoids bears a symphyseal fossa, whereas the ventral processes are well fused (Hiller and Mannering, 2005). This suggests that fusion of the coracoids in elasmosaurids can occur both dorsoventrally or ventrodorsally during ontogeny. In any case, the presence of separated portions along the coracoid symphysis is apparently a feature of adult individuals.

Proximal phalanges of the hind limbs and forelimbs are similar to $A$. parvidens in their massive articular facets (compared with other elasmosaurids) having elongate, spool-shaped elements. Nevertheless, phalanges of the forelimbs are comparatively less well ossified than those of the hind limbs, and their periosteal surface is weakly developed. The presence of reduced ossification in phalanges (as well as reduced mesopodial ossification) was described by Caldwell (1997) as a feature of adult limb morphology, because ossification is generally delayed. Based on these facts, the skeleton described here (SGO.PV.957) is a young adult, comparatively younger than the holotype of $A$. parvidens, but older than the referred specimen of A. quiriquinensis (SGO.PV.260).

\section{DESCRIPTION}

\section{Skull}

The skull of SGO.PV.957 (Fig. 4) was affected during burial by fracture and anterior displacement of the right half of the neurocranium, the atlas-axis and two anterior cervicals shifted anteriorly onto the head. The rostrum and most of the anterodorsal portion of the skull were lost due to tidal erosion, although a fragment of the right maxilla is preserved and includes the anterodorsal portion of the right orbit. In addition to the fracture and displacement, the skull and anterior cervicals were secondarily crushed after burial. Most of the posterior portion of the skull is preserved, as is most of the mandible.

In dorsal view (Fig. 4), the largest bone is the left parietal. It lies laterally crushed to the right, indicating that the skull possessed a relatively high sagittal crest. The dorsal portion of the parietal broadens anteriorly, preserving a pineal foramen that is anteroposteriorly extended and posteriorly thin, and is enclosed only by the parietals. The internal surface of the braincase is exposed in anterodorsal view (Fig. 5). The dorsum sellae is a flat surface 

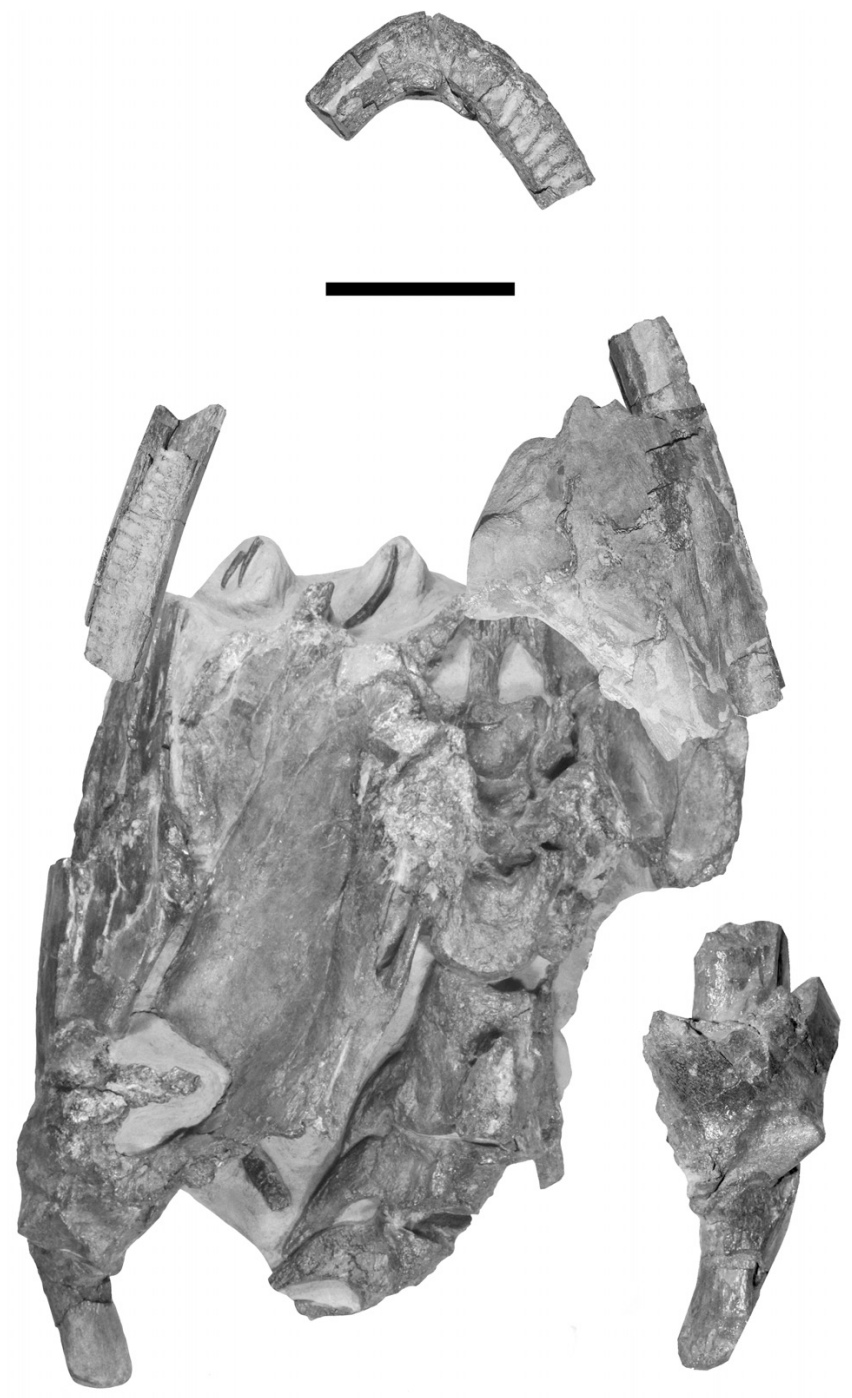

FIGURE 4. Aristonectes quiriquinensis, sp. nov. (SGO.PV.957, holotype). Composite picture showing the dorsal view of the skull, mandibles, and anterior-most cervical elements in anatomical position. Scale bar equals $100 \mathrm{~mm}$.

anterior to the foramen magnum, with a circular pit preserved in its right side, interpreted as the posterior vertical semicircular canal. The sella turcica is rounded and equally broad as it is long. A large portion of the right pterygoid is preserved, which is mostly flat, but has a dorsal (internal) keel near its medial end, giving it a 'dished' aspect. The interpterygoid vacuities are as broad as long, with a distinctive triangular outline. The parasphenoid is a flat bar, longer than broad, which medially separates the interpterygoid vacuities, preserving the suture with each pterygoid. Although the anterior margin of the parasphenoid is not preserved, the reduced breadth of this latter between each pterygoid indicates that the parasphenoid was completely enclosed anteriorly by the pterygoids, which is a feature observed in other elasmosaurids (O'Keefe, 2001:fig. 21). In the right side of the skull, the ectopterygoid is elevated from the pterygoid, and bears the double suture between the ectopterygoid, the pterygoid, and the palatine, the latter represented by a small fragment, whereas the left pala- tine is more complete and partially covered by the disarticulated parietal. Underneath the parietal lies a massive bone, probably the right maxilla. Three teeth are scattered in the matrix below the anterior portion of the preserved skull.

The right portion of the braincase (Fig. 6A) is anteroposteriorly crushed with its anterodorsal portion eroded: the basioccipital is shifted into the skull anteriorly. Because the supraoccipital is eroded and the basioccipital is crushed, the foramen magnum is exposed almost in dorsal view. The occipital condyle is almost complete, being dorsally flattened, although is slightly eroded; its base is demarcated from the basioccipital body by a soft encircling groove, resulting in a constricted appearance in dorsal view. Because of the enclosing matrix, it is not clear whether this groove continues on to the ventral surface of the basioccipital. The basioccipital is better observed on the right side, whereas its left portion is under the left parietal. This is a massive bone, with its lateral portions slightly recurved posteriorly. A noticeable feature is the absence of an anteroposterior constriction between the occipital condyle on the lateral margin of the basioccipital, contrary to the condition described in 'Morturneria seymourensis' (Chatterjee and Small, 1989:fig. 7). The right exoccipital-opisthotic is crushed and dorsally eroded, but part of its posterior suture with the basioccipital is still visible. This element is $20 \%$ taller dorsoventrally than laterally broad. No nerve foramina are visible, and these may have collapsed due to crushing. A small portion of the supraoccipital is preserved, bearing a large foramen near the contact with the right exoccipital-opisthotic, which is interpreted as the posterior vertical semicircular canal. Only the proximal portion of the right paroccipital process is preserved, and is about $50 \%$ thinner than the body of the exoccipital-opisthotic. The exoccipital-opisthotic retains its original orientation with respect to the paroccipital process, showing that the latter was oriented ventrally and slightly recurved in a posterior direction before the crushing. The length of the paroccipital process cannot be determined due its incompleteness.

The left posterior end of the braincase remains in contact with the squamosal, forming an arch that is not entirely preserved (Fig. 6B), although it is possible to see that the squamosal covers the quadrate medially. An internal dorsoventral bone layer appears in the squamosal, disposed parallel to the squamosal-parietal arch. Its dorsal portion is lost, but indicates that the squamosal had a dorsal thickening, giving it a massive aspect. Isolated and embedded in the matrix is a thin, elongate bone with poor ossification, probably a hyoid. A separate fragment preserves the right posterior end of the skull in anatomical position with the posterior right ramus of the mandible, allowing a view of the squamosal covering the quadrate, whereas the articulation between this quadrate and the articular is displaced laterally.

Separated from the skull block is a fragment of the maxilla (Fig. 7A) preserving part of the anterior margin of the orbit, which is slightly rounded. The dorsal surface bears several large foramina near the occlusal margin. In ventral view, this fragment displays 10 alveoli and the casts of several alveoli of the left dentary, produced by the pressure of the overburden, which indicates that the occlusal surface of the dentaries was lost prior to burial.

\section{Teeth}

Nine disarticulated teeth were recovered from the matrix during preparation (Fig. 7B-F). The largest tooth $(56 \mathrm{~mm}$ from the tip of the crown to the end of the root) is extremely slender and pointed, having a crown that bears ridges on the lingual face, whereas the labial face has softer ridges and profuse longitudinal cracking over the enamel due to taphonomy. The smallest $(21 \mathrm{~mm})$ is a replacement tooth with a short root (incomplete), with ornamentation identical to the largest tooth. All of the recovered teeth are 


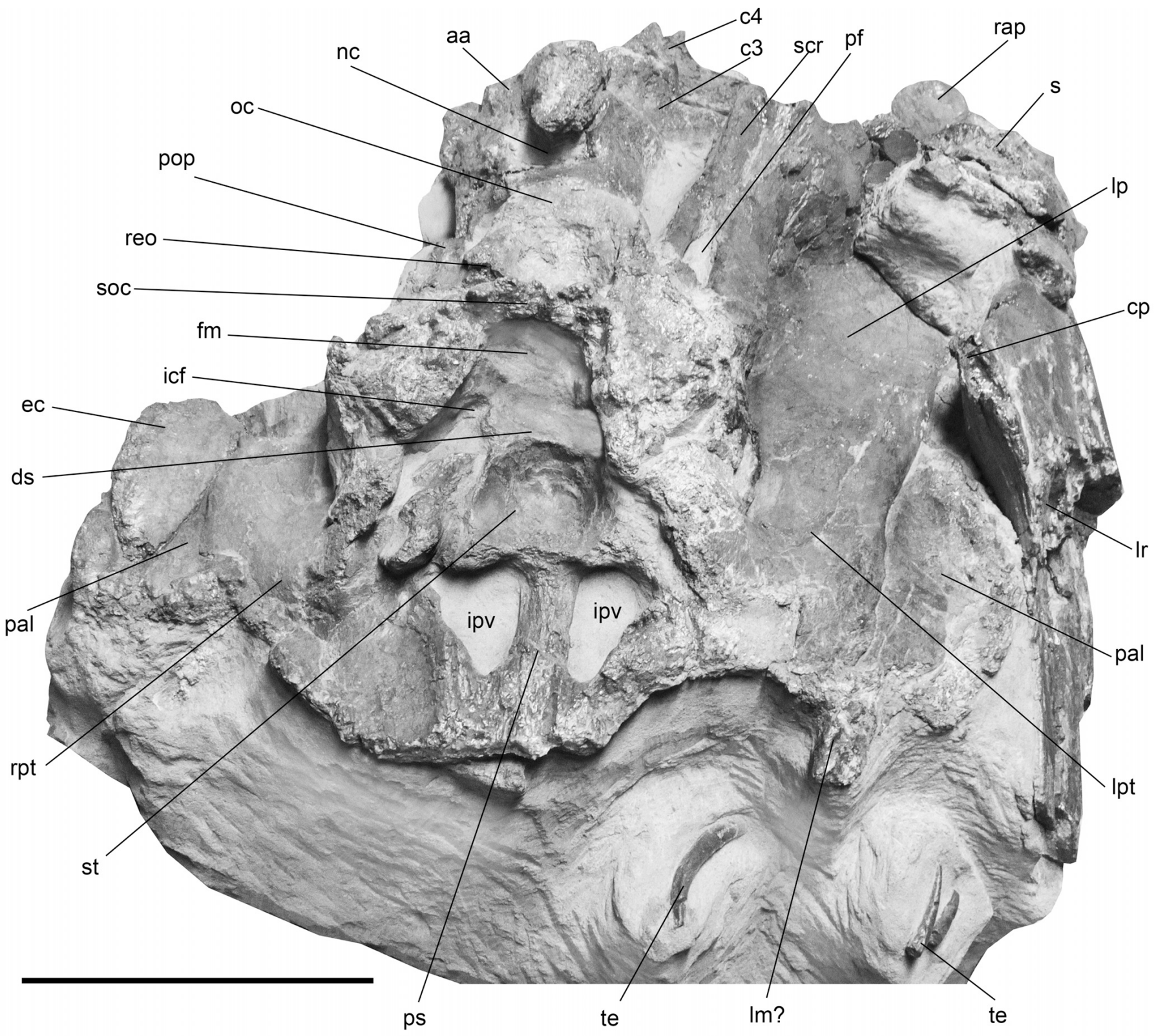

FIGURE 5. Aristonectes quiriquinensis, sp. nov. (SGO.PV.957, holotype). Anterodorsal view of the skull. Scale bar equals $100 \mathrm{~mm}$.

homodont and bear an oval cross-section, and are broader labiolingually than mesiodistally. This morphology is present in other elasmosaurids from the Northern Hemisphere (Welles, 1952) as well as in elasmosaurids from the WBP such as Kaiwhekea katiki (Cruickshank and Fordyce, 2002). The length of the root in the complete teeth is slightly longer than the crown.

\section{Mandible}

The mandible remained in anatomical position when discovered, but its upper surface is lost, probably due to erosion before burial. The alveoli are exposed in occlusal view, and are almost horizontal (procumbent). The symphysis is preserved, as are two anterior fragments of each mandibular ramus, most of the posterior half of the left ramus, and the posterior-most portion of the right ramus. The general aspect of the mandible is slender (Fig. 8A-C). The symphysis is short and unreinforced, although the number of teeth in the symphysis is impossible to determine due to erosion. The symphysis is robust and has a triangular crosssection. The medial surface is almost flat, without any prominence or platform. The left side is eroded, whereas the right side bears 12 regularly distributed, homodont alveoli for small teeth. In lateral view, the symphysis is anteriorly rounded, becoming thicker posteriorly, which gives it a rounded profile, and it bears large foramina on its surface. The ventral surface of the symphysis displays a mental boss (Fig. 8F) that broadens posteriorly and does not reach the internal (lingual) surface. Similar structures have been described in other plesiosaurians; a ventral keel in the mandibular symphysis was also described in Eromangasaurus australis (Kear, 2005:fig. 6; Kear, 2007:fig. 1B), from the middle-late 

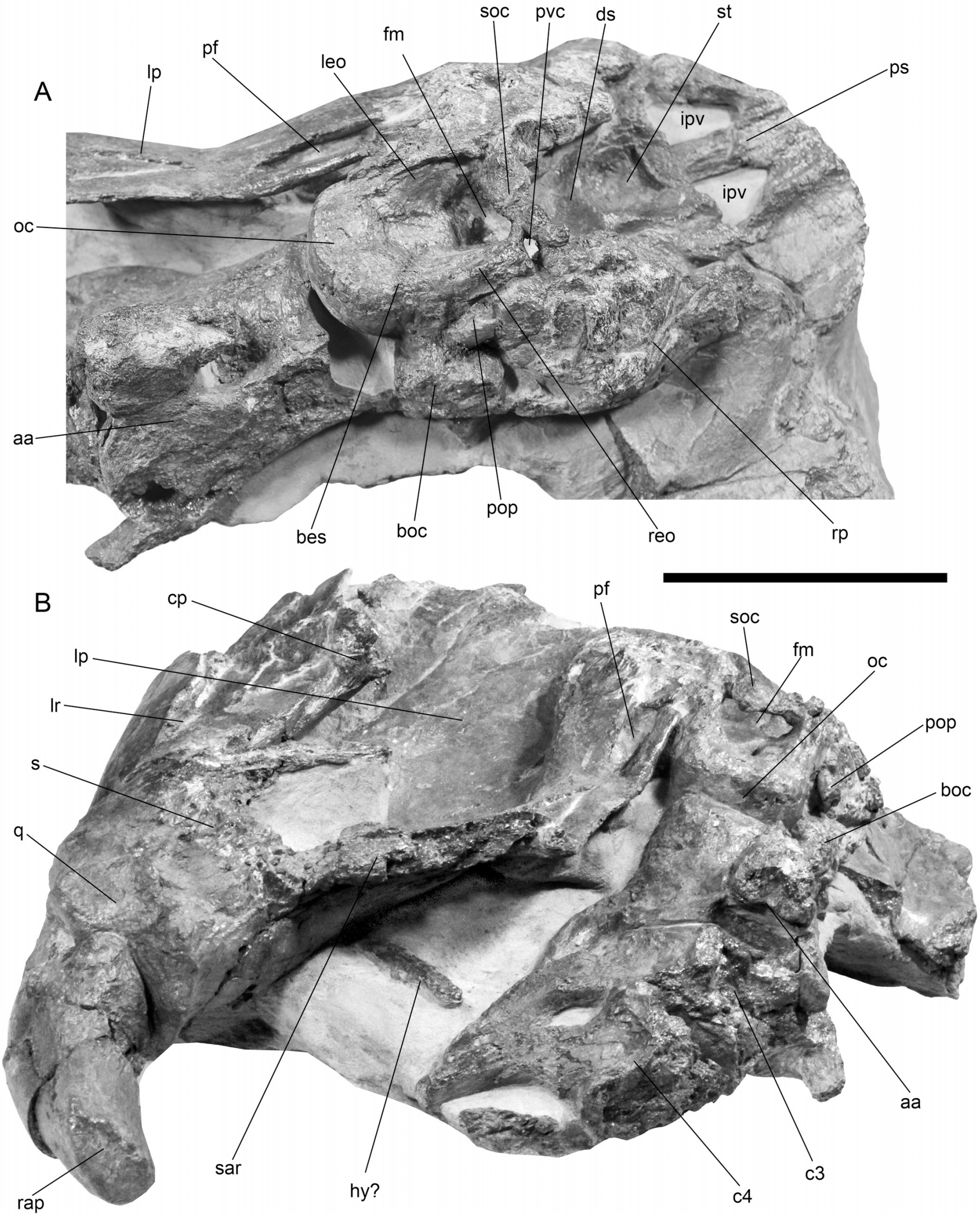

FIGURE 6. Aristonectes quiriquinensis, sp. nov. (SGO.PV.957, holotype). A, right dorsolateral view of the braincase portion; B, occipital view of the skull and anterior cervical elements. Scale bar equals $100 \mathrm{~mm}$. 

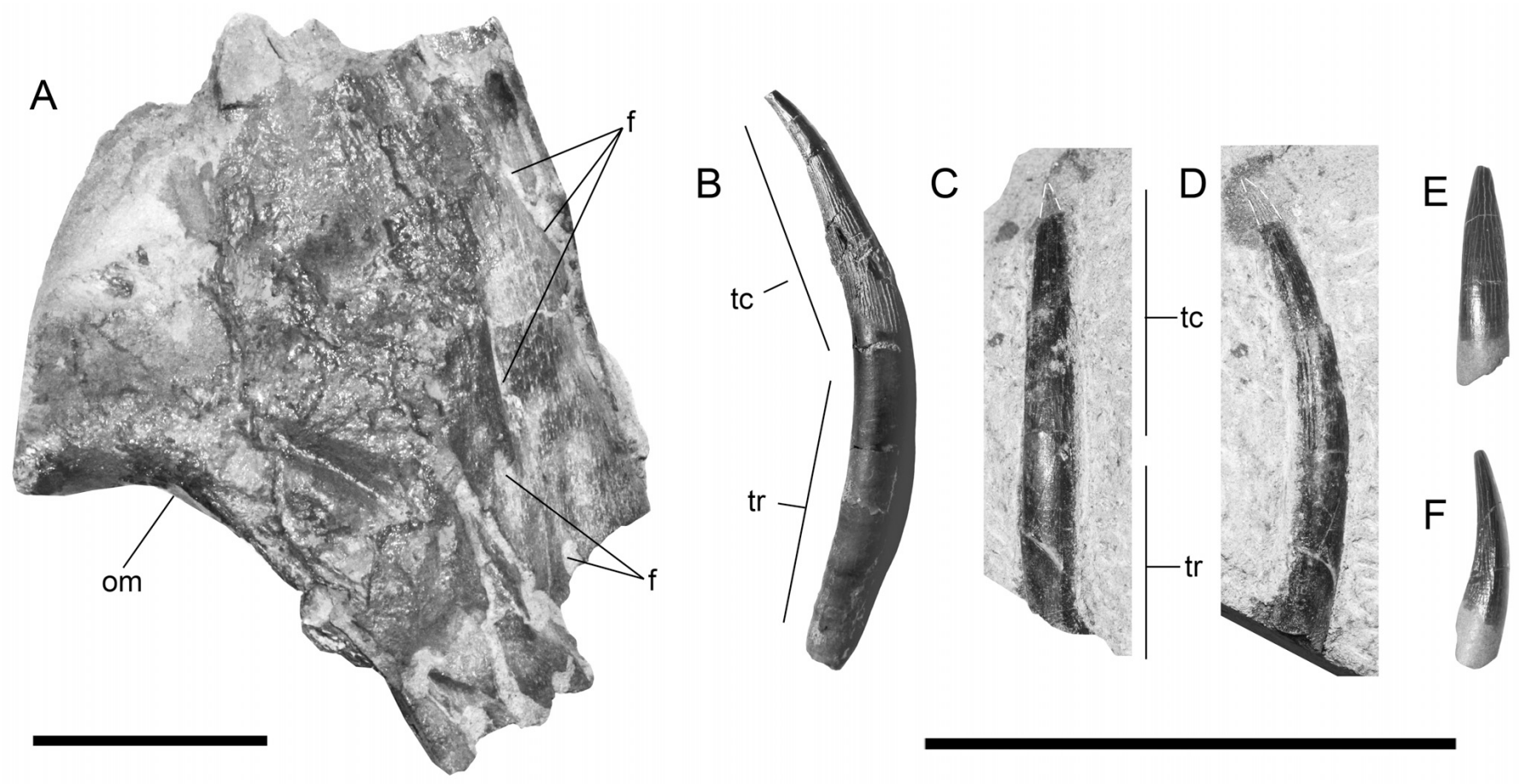

FIGURE 7. Aristonectes quiriquinensis, sp. nov. (SGO.PV.957, holotype). A, dorsal view of the preserved portion of the right maxilla; B, largest tooth recovered, in profile view; $\mathbf{C}$, isolated complete tooth in labial view; $\mathbf{D}$, profile view; $\mathbf{E}$, isolated, replacement tooth in labial view; $\mathbf{F}$, profile view. Scale bars equal $50 \mathrm{~mm}$.

Albian of Queensland, Australia. Interestingly, in Futabasaurus suzukii from the Santonian of Japan, the ventral symphysis of the dentaries bears a heart-shaped pit regarded by these authors as of unknown origin (Sato et al., 2006:fig. 4c). In addition, the anteroventral portion of the mandibles in A. quiriquinensis bears a crenulated edge interpreted as a muscle attachment site. The latter, together with the mental boss, is similar to the ' $Y$ '-shaped edges present in the ventral dentary symphysis in Zarafasaura oceanis (Vincent et al., 2010:fig. 5G) from the upper Maastrichtian of Morocco. Such morphological disparity shows that the muscular attachments over the ventral surface of the anterior mandible are especially diverse among elasmosaurids.

The mandibular rami are both incomplete, comprising an anterior fragment from each side. The left fragment preserves 16 alveoli, whereas the left has 25 . Both fragments are laterally compressed, with a striated labial (external) surface, lacking any foramina, which seems to be restricted to the anterior portion of the mandible. The lingual (internal) surface bears a deep sulcus interpreted as the Meckelian groove based on the cross-sections of the fragments. The posterior cross-section of each ramus (Fig. 8G, $\mathrm{H})$ shows that the dentary forms most of the mandible by occupying the dorsal (occlusal) portion and by having a labial lamina that covers all the lateral surface of the ramus, enclosing the anterior projection of the angular, which is laterally compressed and high. The dentaries also bear a ventrolingual projection that dorsally encloses the Meckelian canal. The splenial is on the ventral margin of the ramus and has a 'C'-shaped cross-section with the ventral portion reduced to a thin layer, whereas the lingual portion is thicker. The contact between this thick section of the splenial and the dorsal projection of the angular joins to the sharp ventral projection of the dentaries. This leaves the Meckelian canal with a triangular cross-section along the preserved portion of each ramus. The anterior cross-section of the left ramus shows that it is slightly compressed dorsoventrally due the medial separation observed between the labial lamina of the dentary, the articular, and the splenial. The dentary has a reduced ventrolingual projection that progressively occupies a larger portion of the mandible, whereas the symphysis comprises only the dentaries. The splenial does not participate in the symphysis, although its anterior-most point on the medial surface extends to a point approximately $40 \mathrm{~mm}$ from the symphysis, underlying the eighth or ninth alveolus. The alveoli are embedded in a cancellous tissue formed by the ossification of the dental lamina, which is covered on its medial side by a rugose tissue that forms the paradental plate (Ketchum and Benson, 2011a, 2011b). This difference in texture gives the appearance of two separate bones.

The posterior portion of each ramus is well preserved, with the left being the most complete. The right posterior end preserves the ramus attached to the posterior portion of the skull (Fig. 9A-C). The squamosal and quadrate are vertically crushed and overlie the ramus, which preserves the complete retroarticular process. This is dorsoventrally compressed, and preserves most of the angularsurangular suture, which extends to a point near the retroarticular end. The coronoid process is preserved, being laterally flattened, with a dorsoventral height twice the average length of the mandible, and having two dorsal projections like those observed in 'Morturneria seymourensis' (Chatterjee and Small, 1989:fig. 6d), although the latter were not properly described in the original description. In anterior view, the surangular and the articular are visible, showing the Meckelian groove (Fig. 9D). In the left posterior ramus (Fig. 9E), the splenial and dentary are poorly preserved, whereas the better-preserved bone displays most of the 
A

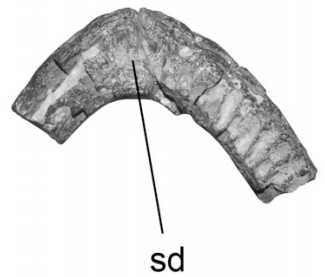

Id
B
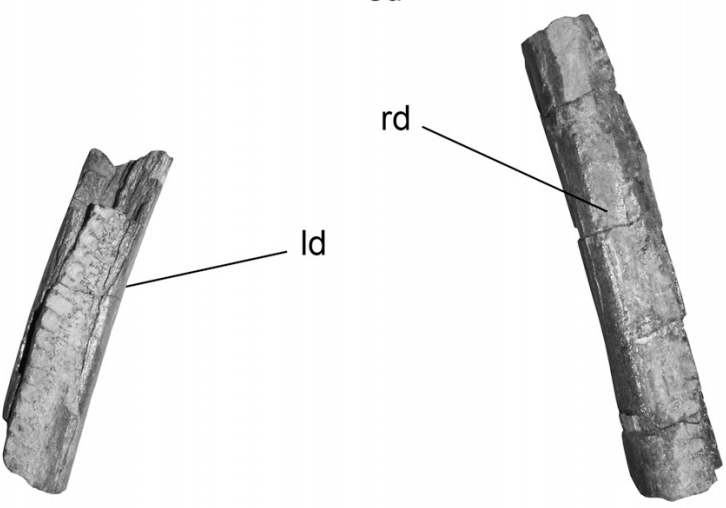

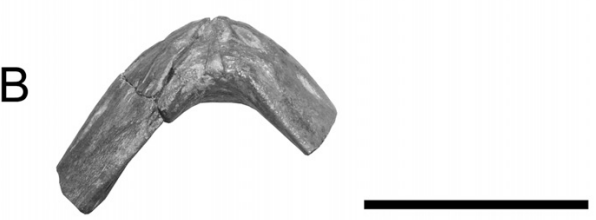

C
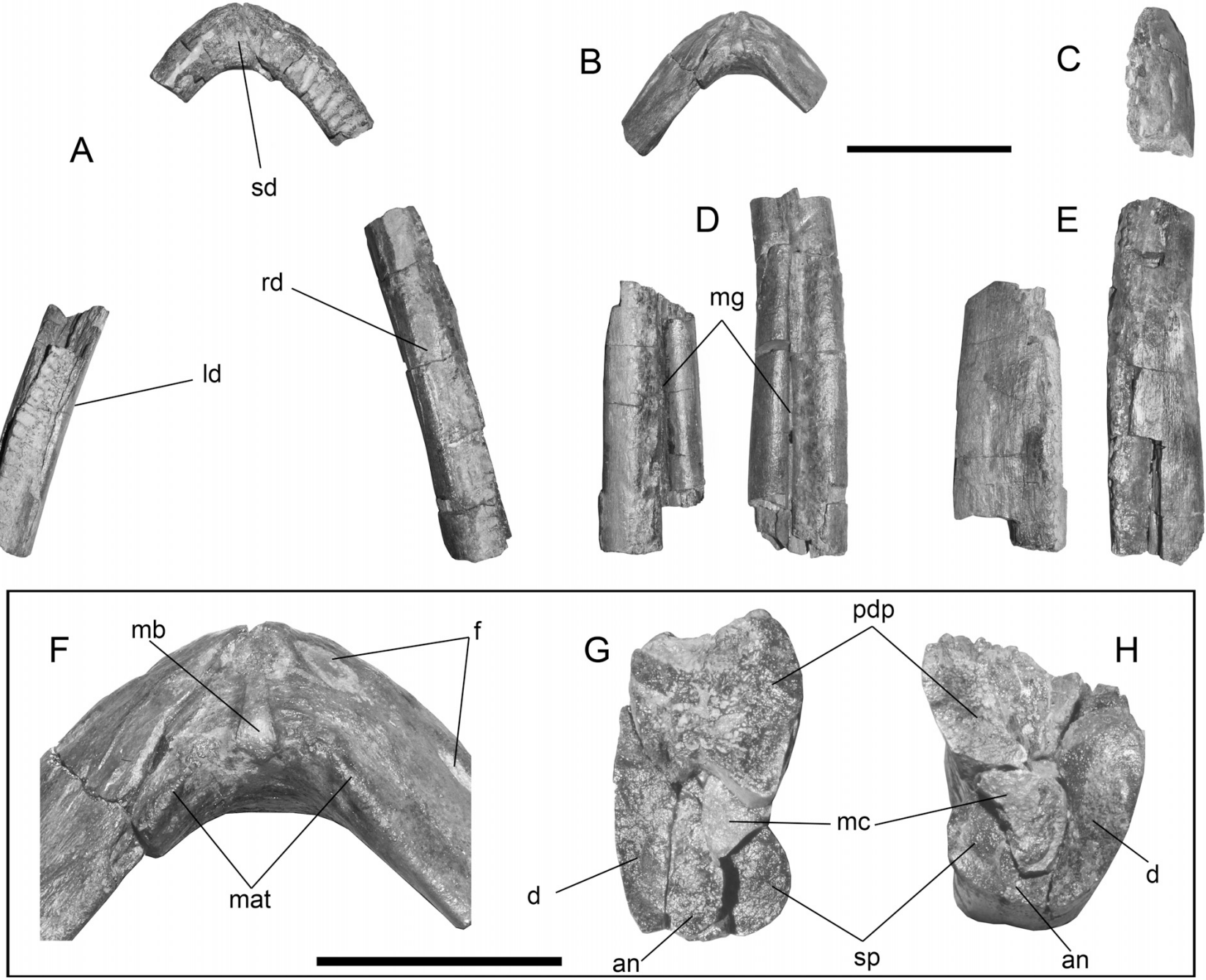

FIGURE 8. Aristonectes quiriquinensis, sp. nov. (SGO.PV.957, holotype). A, occlusal aspect of the mandible fragments; $\mathbf{B}$, ventral view of the symphysis; $\mathbf{C}$, right lateral view of the symphysis; $\mathbf{D}$, lingual view of the lateral portions of each mandibular ramus; $\mathbf{E}$, labial view of the previous; $\mathbf{F}$, ventral detail of the symphysis; $\mathbf{G}$, posterior cross-section of the portion of the left ramus; $\mathbf{H}$, same portion of the left ramus in anterior view. Scale bars equal $50 \mathrm{~mm}$.

suture between the dentary and the surangular, missing only the ventral portion bearing the contact between the angular and the splenial. The retroarticular processes are elongated, flattened, and conspicuously angled dorsomedially, having their posterior ends slightly expanded. The asymmetry between the retroarticular processes is another noteworthy feature, with the right more flattened and laterally expanded than the left. Such differences are hard to explain taphonomically and could be pathological.

The alveoli are best preserved in the right ramus of the mandible, which includes 37 preserved alveoli in the symphysis and anterior dentary. They are all similar in size and have a density of about thirteen alveoli per 10 -cm section. Four poorly preserved alveoli appear to be present in the right dentary fragment, whereas the absent portion between this and the symphyseal portion could have included 5-10 additional teeth, bringing the total number close to 50. The posterior portions of the dentaries are not preserved, and in consequence, the estimated number of teeth in the dentaries could be higher than 50. However, the last alveoli in $A$. parvidens are placed about $60-65 \mathrm{~mm}$ anterior to the highest portion of the right ramus, whereas in the holotype of $A$. quiriquinensis the portion anterior to the coronoid is broken and exposed in a longitudinal section of about $130 \mathrm{~mm}$, where no evidence of any alveolus is observed. This suggests that $A$. quiriquinensis may have been characterized by a reduced number of dentary teeth compared with $A$. parvidens. This estimated tooth number is intermediate between the 42-44 dentary teeth of $K$. katiki (Cruickshank and Fordyce, 2002) and the 65 dentary teeth of $A$. parvidens (Gasparini et al., 2003a). These numbers are higher than those recorded in other elasmosaurids such as Tuarangisaurus keyesi (14-15) (Wiffen and Moisley, 1986) and Terminonatator ponteixensis (17-18) (Sato, 2003).

\section{Axial Skeleton}

The holotype specimen preserves 37 cervicals (including the atlas-axis), 12 of which are from the anterior portion, and 23 from 

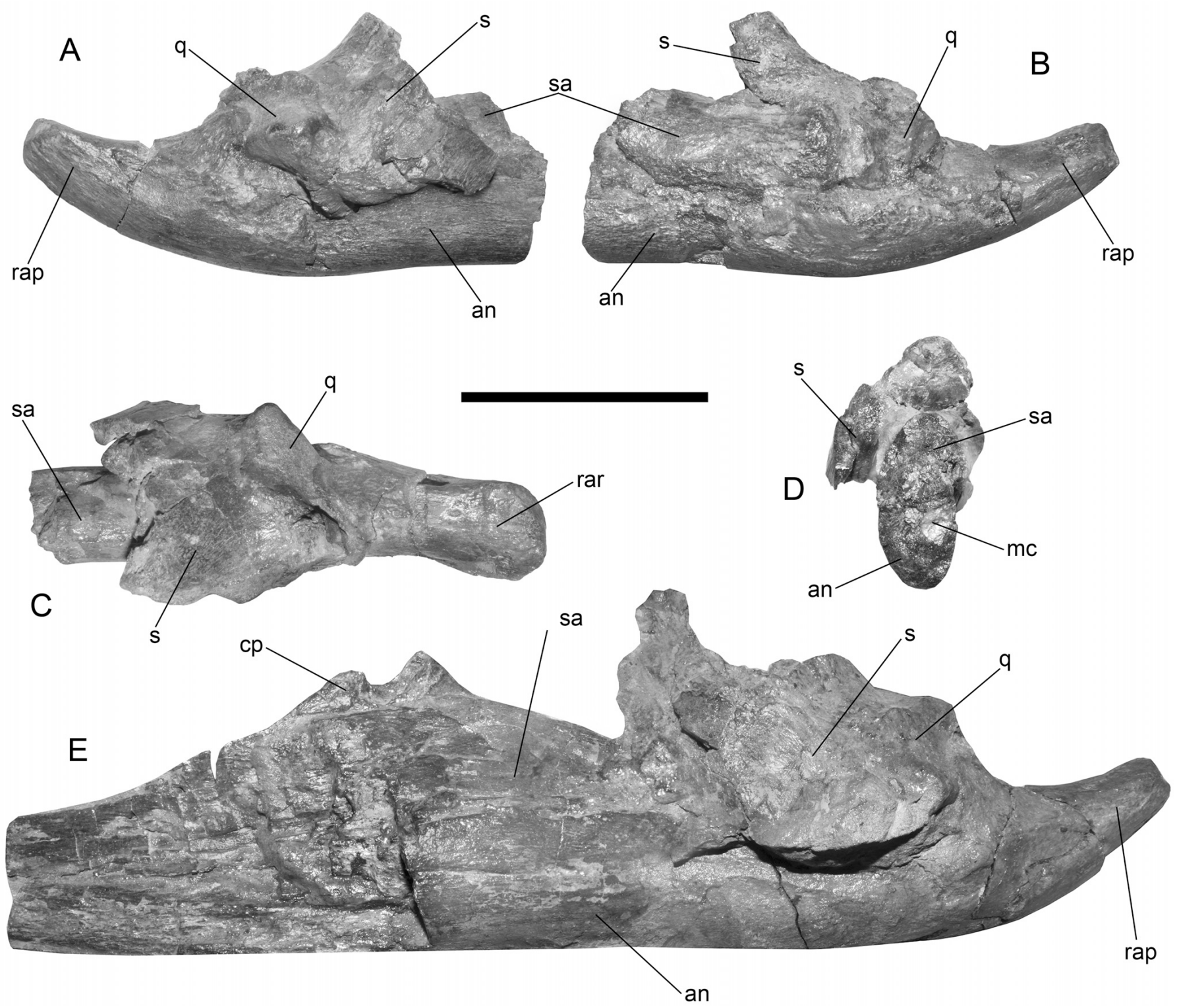

FIGURE 9. Aristonectes quiriquinensis, sp. nov. (SGO.PV.957, holotype). A, posterior right ramus in labial view; B, lingual view; C, dorsal view; D, anterior cross-section view of the posterior portion of the right ramus; $\mathbf{E}$, posterior portion of the left ramus in labial view. Scale bar equals $100 \mathrm{~mm}$.

the middle-posterior series. The available measurements of all axial centra are presented in Table 1.

Atlas-axis Complex-This element remains articulated with the occipital condyle and cervicals 3 and 4 . These elements are partially crushed dorsoventrally. The atlas-axis complex is longer than it is wide or high, with a well-excavated atlantal cup. The atlas arch lacks its dorsal portion, although the pedicels are present. The ventral portion of the atlas arch covers the atlas centrum laterally in its anterior portion. The atlas intercentrum forms the ventral zone of the atlantal cup, and it is also exposed laterally between the atlas arch and the axis centrum. The axis centrum is laterally exposed posteriorly, with an anteroposteriorly trending neurocentral suture, whereas the contact with the atlas centrum bears a weak diagonal suture in lateral view. The contacts among these elements are similar to those of $A$. parvidens, although in this latter species the axis centrum and the axis arch are separated by a dorsoposterior projection of the atlas centrum (Gasparini et al., 2003a:fig.3E), whereas in A. quiriquinensis the axis centrum and its arch are in contact. The ventral surface cannot be observed because it remains in the matrix, and the ventral contacts of the complex are impossible to determine. The most striking feature of the atlas-axis complex is the presence of a large transverse process composed of equal contributions from the ribs of the atlas centrum and intercentrum (Fig. 10A-D). This condition differs from $A$. parvidens, where the rib of the atlas centrum fades before the contact between the atlas-axis and the third cervical. The distal end of the atlas-axis rib has a facet that contacts the rib of the third cervical vertebra.

Anterior Cervical Vertebrae-There are 12 anterior cervical vertebrae preserved (posterior to the atlas-axis complex) and 
TABLE 1. Measurements of vertebral centra.

\begin{tabular}{|c|c|c|c|c|c|c|c|}
\hline Block & Cervical vertebrae & Length & Height & Breadth & VLI & HI & BI \\
\hline Skull block & aа & 94.5 & $66.0^{*}$ & $76.0^{*}$ & 69.8412698 & 133.098592 & 80.4232804 \\
\hline Skull block & 3 & 46.1 & $53.8^{*}$ & $67.4^{*}$ & 76.0726073 & 116.70282 & 146.203905 \\
\hline Skull block & 4 & 52.4 & - & - & - & - & - \\
\hline Block 1 & 6 & - & - & - & - & - & - \\
\hline Block 2 & 7 & 56.7 & 54.5 & 75.3 & 87.3651772 & 96.1199295 & 132.804233 \\
\hline Block 2 & 8 & 54.5 & 58.4 & 77.3 & 80.3242447 & 107.155963 & 141.834862 \\
\hline Isolated & 9 & - & - & 76.6 & - & - & - \\
\hline Block 4 & 12 & - & - & - & - & - & - \\
\hline Block 4 & 13 & - & - & - & - & - & - \\
\hline Block 4 & 14 & - & - & - & - & - & - \\
\hline Isolated & 15 & - & 90.5 & - & - & - & - \\
\hline Block 5 & 16 & - & 89.2 & - & - & - & - \\
\hline Block 5 & 17 & 82.0 & $81.1^{*}$ & $91.4^{*}$ & 95.0724638 & 98.902439 & 111.463415 \\
\hline Block 6 & 20 & $80.2^{*}$ & $81.8^{*}$ & - & - & 101.995012 & - \\
\hline Isolated & 24 & 73.5 & - & - & - & - & - \\
\hline Isolated & 25 & - & - & - & - & - & - \\
\hline Isolated & 26 & - & - & - & - & - & - \\
\hline Block 8 & 27 & 84.5 & $95.5^{*}$ & - & - & 113.017751 & - \\
\hline Block 8 & 28 & 83.0 & $100.3^{*}$ & $113.3^{*}$ & 77.7153558 & 120.843373 & 136.506024 \\
\hline Block 8 & 29 & 82.7 & $113.2^{*}$ & $120.7^{*}$ & 70.7139803 & 136.88029 & 145.949214 \\
\hline Block 9 & 30 & $83.2^{*}$ & $104.6^{*}$ & $133.8^{*}$ & 63.7126049 & 152.917207 & 155.392404 \\
\hline Block 9 & 31 & $85.5^{*}$ & $102.4^{*}$ & $133.9^{*}$ & 56.7112294 & 168.954124 & 164.835594 \\
\hline Block 9 & 32 & $86.6^{*}$ & $111.4^{*}$ & $129.4^{*}$ & 49.7098539 & 184.99104 & 174.278784 \\
\hline Block 10 & 33 & 88 & - & - & - & - & - \\
\hline Block 10 & 34 & 78.9* & - & - & - & - & - \\
\hline Block 11 & 35 & 87.1 & - & - & - & - & - \\
\hline Block 11 & 36 & 88.3 & - & - & - & - & - \\
\hline \multirow[t]{2}{*}{ Block 11} & 37 & - & - & - & - & - & - \\
\hline & Dorsal vertebrae & & & & & & \\
\hline Block 15 & 45 & 108.6 & 39 & - & - & 35.9116022 & - \\
\hline Block 15 & 46 & - & - & - & - & - & - \\
\hline Block 15 & 45 & 108.6 & - & 39 & - & - & - \\
\hline Block 15 & 46 & - & - & - & - & - & - \\
\hline
\end{tabular}

Data were taken from available exposures in the extracted sediment blocks. Absence of measurements is denoted with a dash, whereas asterisks indicate measurements on deformed elements. Vertebral length index $(\mathrm{VLI})=\mathrm{L} /(0.5 \times(\mathrm{H}+\mathrm{B}))$ from Brown (1981); index of ratio between height and length $(\mathrm{HI})=(100 \times \mathrm{H} / \mathrm{L})$ and index of ratio between breadth and length $(\mathrm{BI})=(100 \times \mathrm{B} / \mathrm{L})$ from Welles $(1952)$.

associated with the skull. The third and fourth centra lie articulated in the skull block, with a small fragment of the fifth cervical. These are much broader than long, but are dorsoventrally crushed. Both preserve only the left part of the centrum, having an oval pedicel for the neural arch. Cervical ribs are displaced laterally due to crushing, but their proximal section indicates that they were directed ventrolaterally in life, as observed in the juvenile referred specimen (Otero et al., 2012:fig. 3C, D). The third cervical has a distal facet that fits the anterolateral surface of the rib in the fourth cervical, which is similar to that present in the atlas-axis rib (Fig. 11A). The fifth and sixth vertebrae are damaged due to erosion. The seventh and eighth cervicals remain articulated and are preserved in an isolated block (Fig. 11B). These cen- tra were deformed by strain in the axial direction but are largely complete, preserving parts of the neural arches. In ventral view, they have two oval foramina that are well separated from the midline without a ventral keel between them (Fig. 11C). A lateral keel is present on each side of both vertebral centra. The ninth cervical vertebra is represented by an isolated articular fragment that verifies the presence of a slightly concave articular surface. The distance between its preserved articular face and its pedicel for the neural arch is similar to that observed in the second cervical, suggesting that the preserved articular surface is the anterior one. The 10th and 11th cervicals are contained in a single block and exposed mostly in left lateral view. These vertebrae are damaged, lacking approximately half of each centrum, but their 


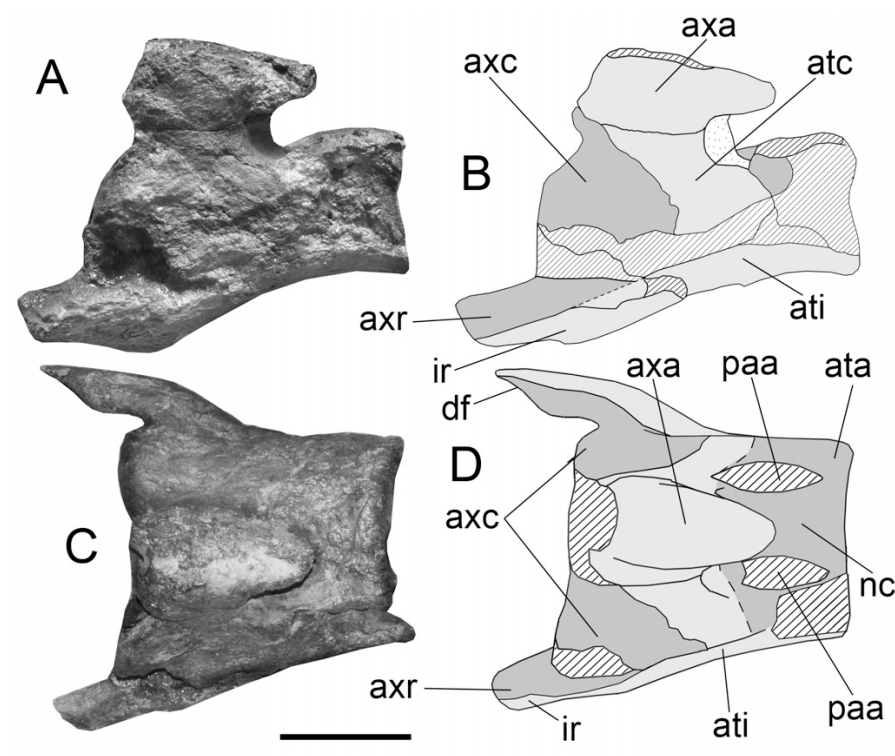

FIGURE 10. Aristonectes quiriquinensis, sp. nov. (SGO.PV.957, holotype). $\mathbf{A}$, atlas-axis in right lateral view; $\mathbf{B}$, interpretative diagram of the atlas-axis in the same view; $\mathbf{C}$, dorsal aspect of the atlas-axis; $\mathbf{D}$, interpretative diagram in the same view. Scale bar equals $50 \mathrm{~mm}$.

neural spines are preserved, and these are short, robust, and angled anteriorly. Although both centra are incomplete, it is possible to identify bilobed articular faces ('dumbbell-shape' of Gasparini et al., 2003a) (Fig. 11D). They are almost amphiplatyan (Fig. 11E), which implies that the transition from amphicoelous to flat articular faces occurred between the ninth and 11th cervicals. The last three anterior cervicals preserved (12th to 14th) are known from three fragments that remain in anatomical position in block 4 , but the major parts of their centra are lost due to erosion.

Middle and Posterior Cervical Vertebrae-This portion of the neck preserves 23 vertebrae with the anterior centra poorly preserved and the left half eroded, whereas successive posterior centra are well preserved due the dipping of the trunk into the silt sandstone (Fig. 12A). The last two centra preserve only their right halves. This portion of the neck is almost complete, except for one centrum that was probably lost during extraction (but is known from its neural spine attached to the following anterior vertebra), and two isolated vertebrae. The centra are broader than long and longer than high (Table 1). The four anterior centra of this portion have their left lateral side eroded and the right side is embedded in the matrix, whereas the four following centra bear a lateral keel that fades posteriorly and is totally absent in the following vertebrae. The most noteworthy feature of the cervical series is the presence of neural spines that are strongly angled anteriorly at around $30^{\circ}$ (Fig. 12A). The neural spines of the middle cervical portion are blade-like and slightly expanded distally. The entire succession is crushed laterally and cervical ribs are cracked and slightly displaced in a ventral direction, even though their proximal portions are retained in anatomical position preserved at angles of nearly $150^{\circ}$ with respect to the neural spines (Fig. 12B). In ventral view, the vertebrae on this block have two oval foramina without a ventral keel between them (Fig. 12C), similar to those observed in the anterior cervicals. Successive vertebrae preserved in the fourth block have similar articular facets and ribs with similar angles with respect to the neural spines (Fig. 12D), although they start to show larger ventral foramina with broader separation between them (Fig. 12E). The posterior vertebrae of the neck are better preserved in the fifth block, and these possess higher neural spines with a dorsoventrally enlarged neural canal (Fig. 12F). In these, the neural spines have alternating delicate bony flanges on each side (anterior left, posterior right) (Fig. 12G, H), a highly unusual feature in elasmosaurids, but identical to those described for specimen SGO.PV.260 (Otero et al., 2012). Neural spines along the neck do not have dorsoventrally oriented grooves in their posterior margins. Anterior zygapophyses extend anteriorly beyond the plane of the articular surface, interlocking with the following posterior zygapophyses. The latter do not overhang the plane of the posterior articular surface. Cervical ribs are angled anteriorly at about $30^{\circ}$ along the entire preserved portion of the neck, and have expanded distal ends that are better preserved in the anterior-most block. The posterior-most cervical ribs differ substantially from the anterior-most ones, being distally expanded into a very thin bone layer comprised almost exclusively of periosteum.

Dorsal Vertebrae - These are preserved in four blocks from the trunk section, with a total number of 11 centra. The anterior block of this portion has two fragmentary centra, whereas the following block has four centra exposed in ventrolateral view, with the second crushed and the posterior preserving its anterior half. These are associated with four gastralia, fragments of two ribs, the right scapula, and the glenoid portion of the right coracoid. The successive block preserves the left half of three vertebrae exposed in longitudinal section. Their respective neural arches are also preserved. The following five vertebrae are represented only by halves of each centrum preserved in two successive blocks. Dorsal centra are comparatively larger and dorsoventrally taller than the cervicals, and are as high as broad (Table 1). They also bear a medial constriction of each centrum, whereas the articular surfaces are slightly amphicoelous, judging from the centra exposed in longitudinal section. All preserved centra are fused to their neural arches.

\section{Pectoral Girdle}

The pectoral girdle is preserved in 15 blocks separated by saw cuts and attendant fragmentation. Despite this, reconstruction of most of the scapulae and coracoids is possible. The anterior-most block displays four vertebrae in dorsal view and two gastralia, whereas in ventral view it holds most of the right scapula.

Scapulae-The scapulae are preserved in five blocks, two of which contain each posterior portion anatomically articulated with their respective coracoid, whereas the medial processes are known from two other blocks. The scapulae are thin, slightly deformed, and were partially crushed during burial, although their symphyseal ends remained in anatomical position. The midline is not fused, but has a complete contact. The dorsal process of the right scapula is low (Fig. 13A) and slightly shorter than the length of the ventral portion of the scapula. It is also massive and posteriorly angled at approximately $55^{\circ}$ with respect to the horizontal, with two well-defined facets. In lateral view, its anterior margin is slightly concave. The medial process of the right scapula has a caudal projection with a posterior rounded end, indicating that there was no medial contact with the coracoid. In consequence, the pectoral bar is not fully enclosed by the scapula and coracoid. Also, the medial portion of each scapula bears a small projection interpreted as the acromion tuberosity; this is also present in the referred specimen SGO.PV.260 (Fig. 13B, C) and seems to be distinctive for this taxon. There is no evidence of clavicular or interclavicular elements, even though other delicate bones are preserved. These are also unknown in the referred specimen. 


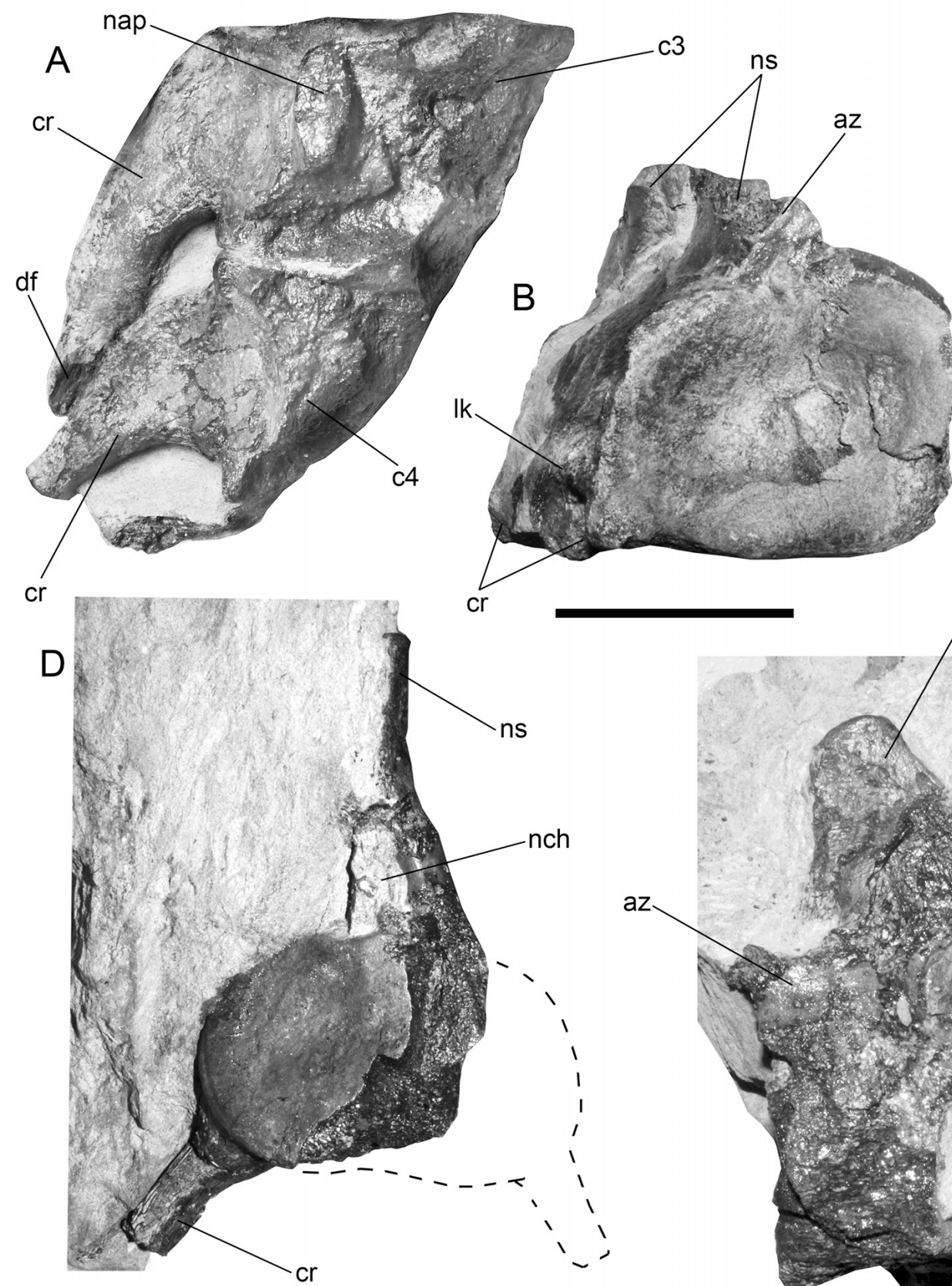
$-13$
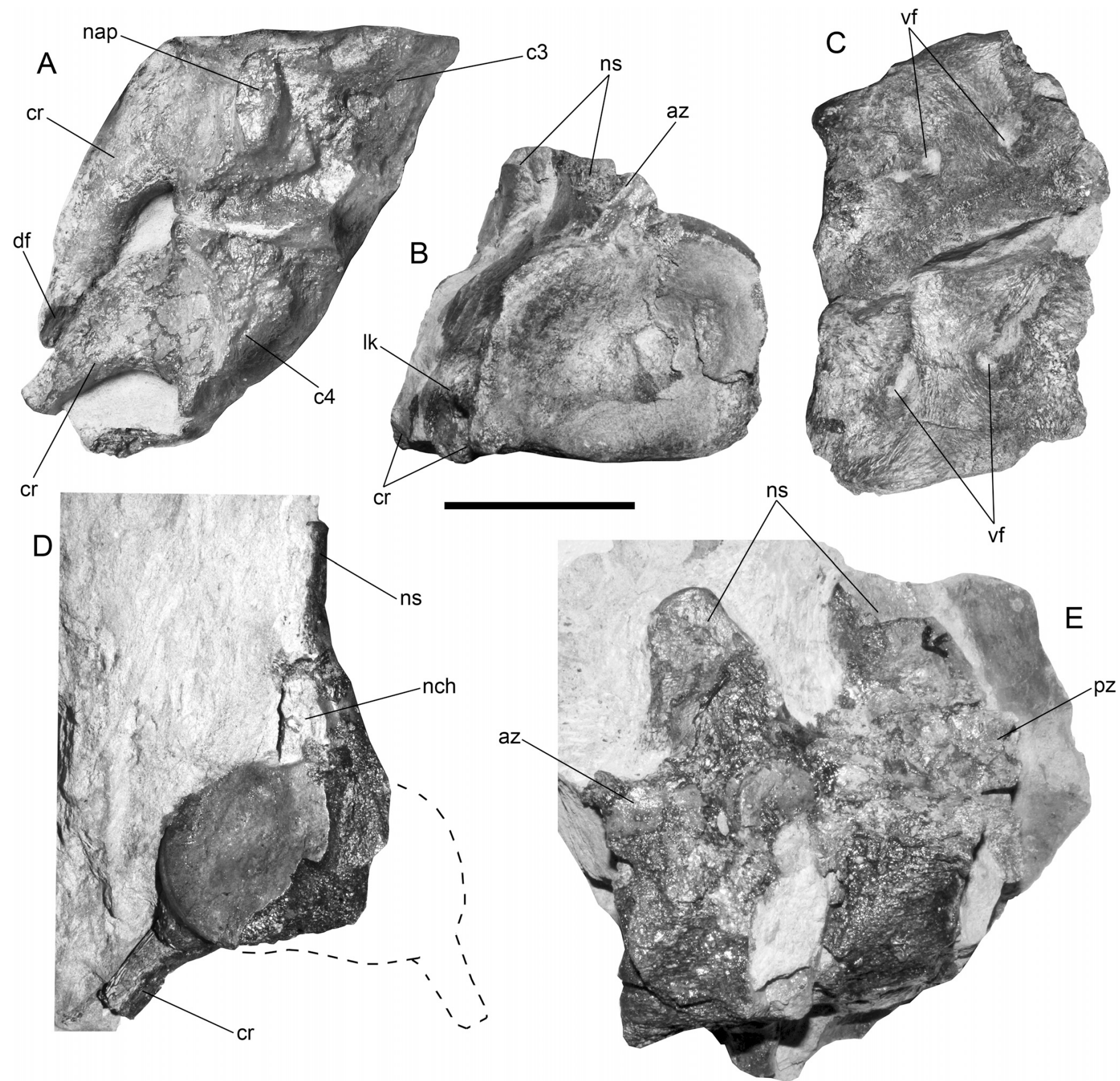

FIGURE 11. Aristonectes quiriquinensis, sp. nov. (SGO.PV.957, holotype). A, third and fourth cervicals in dorsal view; $\mathbf{B}$, seventh cervical in anterior view; $\mathbf{C}$, seventh and eighth cervicals in ventral view; D, 10th cervical in anterior view; $\mathbf{E}, 10$ th and 11th cervicals in left lateral view. Scale bar equals $50 \mathrm{~mm}$.

Coracoids - A large portion of the right coracoid can be reassembled (Fig. 13D), missing only a small fragment of its posterior end and a fragment of the anterior process. The glenoid facet of the coracoid is larger than the scapular one. Also, the cordiform fenestra has a diagonal oval outline and is fully enclosed by the posterior rejoining of both coracoids in the midline. The outline of the best-preserved coracoid (right) is very similar to that of the referred specimen SGO.PV.260 (Fig. 13E), although the cordiform fenestra in the latter is still open due its ontogenetic stage. The morphology of the coracoids has distinctive elements: firstly, the anterior portions are dorsally fused on the midline, whereas its ventral surfaces remain separate. Secondly, the ventral processes are conical and high, which is a feature previously observed in elasmosaurids of the WBP (Welles, 1952, 1962; Hiller and Mannering, 
2005:fig. 7; Hiller et al., 2005:fig. 18B). Both ventral processes are completely separated and taper laterally at their distal ends (Fig. 13F, G), whereas their medial surfaces are rugose. Thirdly, the transverse ridge is much reduced (probably crushed), giving a generally flat appearance to the coracoids in dorsal (visceral) view. Although the pectoral girdle is separated into several blocks (Fig. $13 \mathrm{H})$, these portions were outlined together with the scapular fragments for reconstructing the entire pectoral girdle (Fig. 13I).
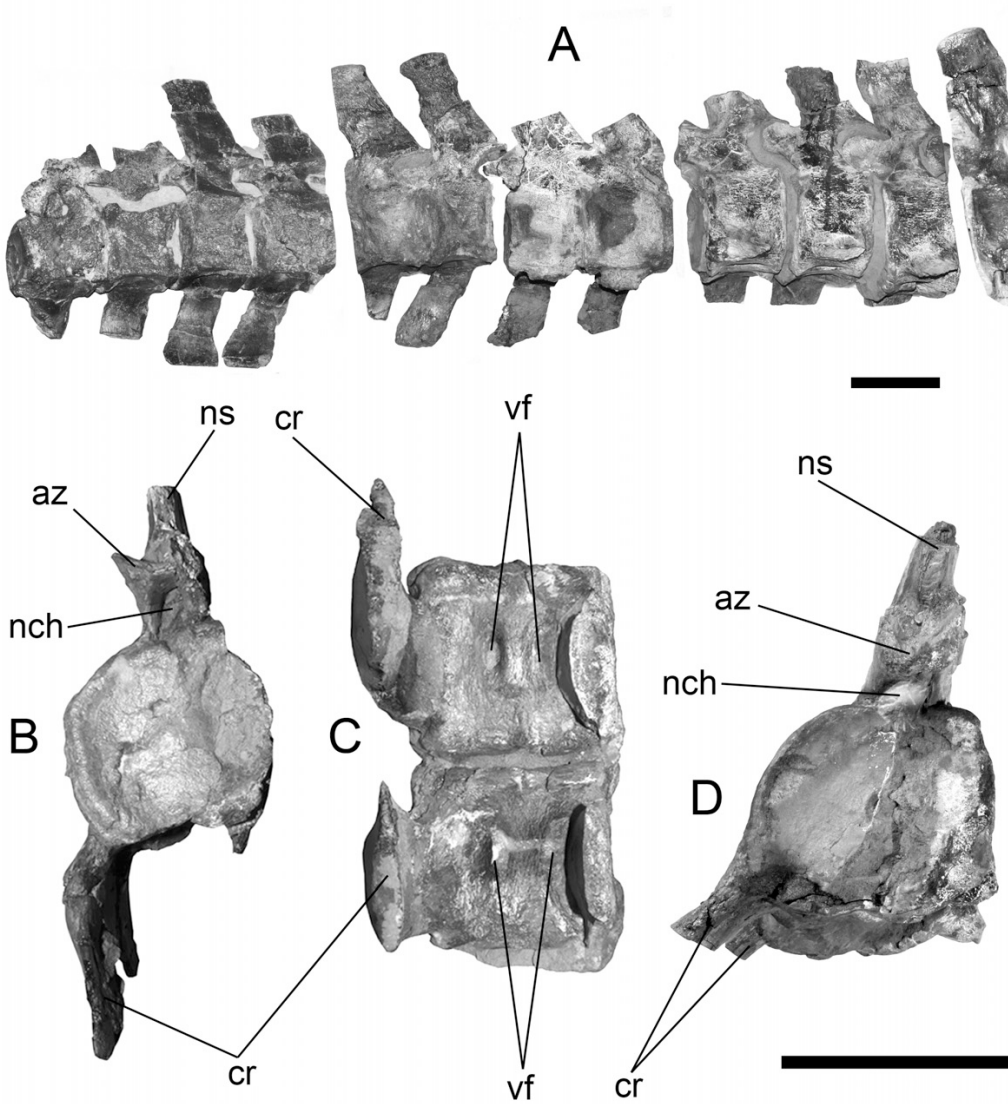

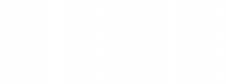

vf

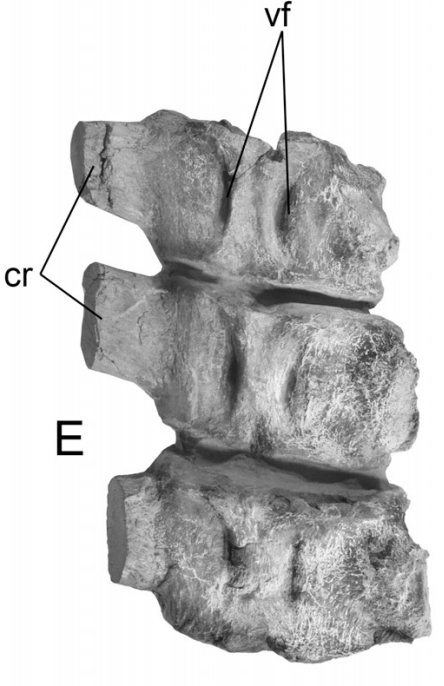

$E$
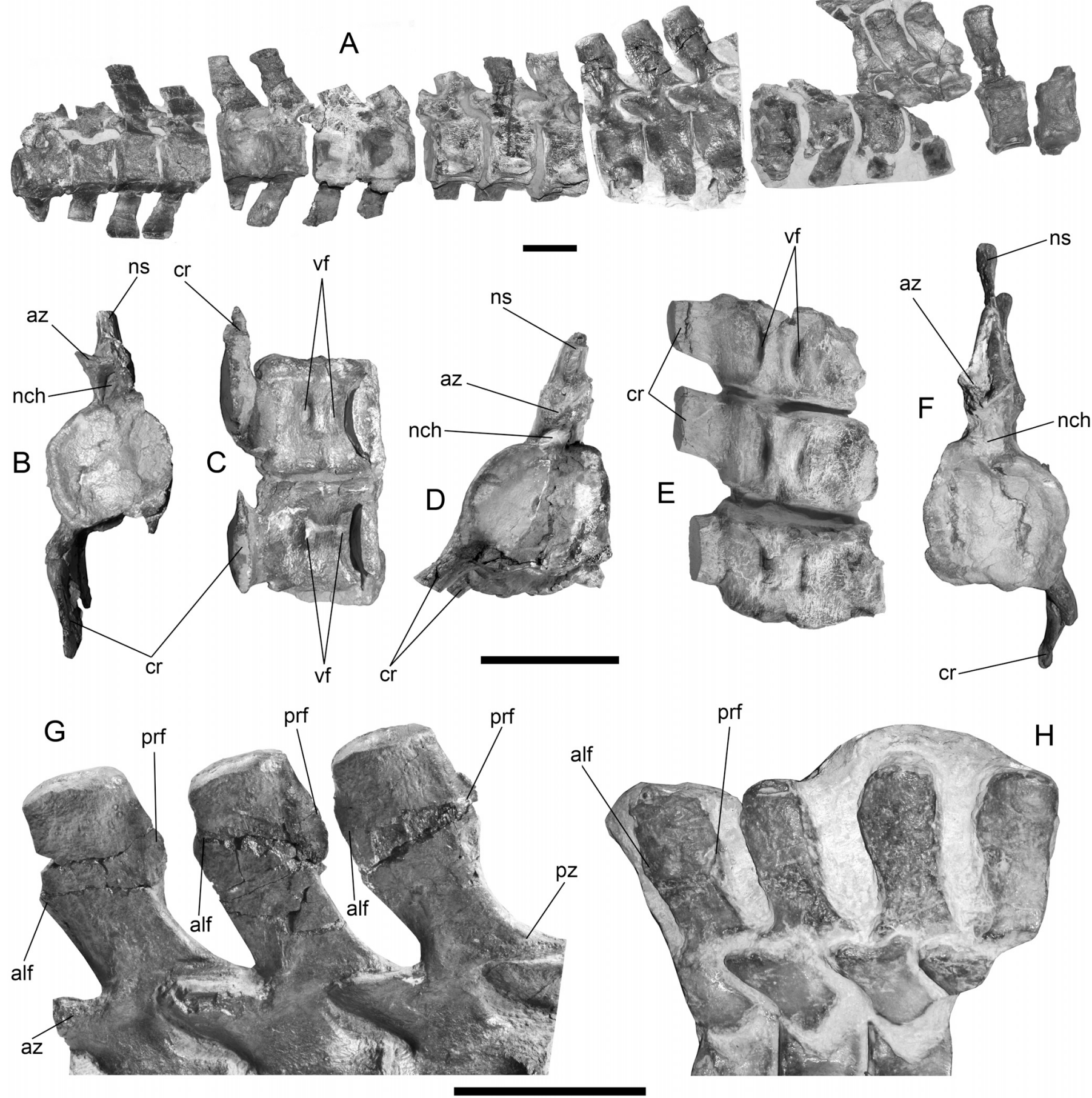

az

prf 


\section{Ribs and Gastralia}

Several ribs and gastralia are present in the holotype specimen. About 20 incomplete gastralia and large fragments are either isolated or included in the different blocks, whereas ribs are scarce and represented by no more than seven elements, which suggests a combination of scavenging and transportation. The ribs are easily distinguished from the gastralia by their better ossification (Fig. 14A) and by a hollow medullary cavity. Their cross-section is circular to oval. Ribs appear to be distally thickened based on the cross-section of two rib portions crushed into the coracoids. There are several ribs of moderate length, very thin and delicate, located in the transition between the neck and the trunk (Fig. 14B); these elements could be partially cartilaginous, as judged by the lack of cancellous bone and the hollow space observed in cross-section. Their number is not accurately known, but they seem to be present in about two or three vertebrae from the cervical-dorsal transition (i.e., pectorals). The gastralia (Fig. 14C-E) are pachyostotic with a moderate lateral length (less than $30 \mathrm{~mm}$ ). Two types are distinguished. One type has a thick dorsal surface and is axially compressed; their ventral surfaces are narrower than their dorsal surfaces. These gastralia are medially thick and thin out towards each side. The second type is straight in outline between the midline and the lateral border of the trunk, but are posteriorly recurved from the lateral border. There is no evidence for a central element or fused gastralia along the ventral portion.

\section{Forelimbs}

The left forelimb is extremely compressed dorsoventrally and its epipodials and mesopodials are comparatively more compressed than the equivalent elements in the right forelimb. This indicates that partial postmortem crushing occurred, although this is not immediately evident, because the distal end of the humerus is not strongly deformed and the phalanges do not appear to be cracked. Nevertheless, perichondral bone was not observed in other elements, which suggests higher plasticity after burial in this portion of the skeleton. The limb may thus have been compressed without showing evidence of crushing. A similarly reduced thickness is also observed in the epipodials and subsequent mesopodials. The phalanges of the forelimbs differ from those of the hind limbs in having a more elongate and gracile shape, independent of their crushing. With these considerations, the distally flattened and biconvex profile of the propodials appears to be more exaggerated in the forelimbs. The dorsal surfaces of the humerus and femur are distinctly convex, with the ventral surface comparatively more convex, despite the eventual crushing of the elements mentioned.

The forelimbs are both known from almost complete anterior extremities (Fig. 15A-D). The humeral shafts are slender and straight. The right humerus is entirely removed from the matrix (Fig. 15E, F), which allows us to observe that the humeral head is curved ventrally, is subhemispherical, and prominent with respect to the rest of the diaphysis. The tuberosity is large and slightly displaced anteriorly with respect to the midline of the diaphysis, whereas an additional muscle attachment is present in the proximal third of the caudal margin in each humerus. The left humerus is crushed and partially detached from the glenoid (Fig. 15G). Both forelimbs include the radius (which is preserved incompletely and dorsoventrally rotated with respect to the humerus in the right forelimb). It shows a lunate outline, is longer than wide, and has a concave border on the preaxial margin that does not bear the distinctive notch observed in other Chilean elasmosaurids (Steinmann et al., 1895; Broili, 1930). The ulna is also lunate, but slightly shorter than the radius. There is a postaxial ossicle in the lateral border of the paddle, which is complete in the right limb and has a semicircular outline. Its anatomical position, adjacent to the posterodistal margin of the ulna and proximal to the ulnare, is compatible with the pisiform of other tetrapods (Romer, 1956; Carroll, 1969, 1981, 1988; Caldwell, 2002). However, due to the absence of more complete ontogenies of the limbs, and the fact that there is an element of similar shape and position in the hind limb, its identification remains unclear. Epipodials and mesopodials remain articulated in both forelimbs. The radiale is better preserved in the left forelimb, and has a subsquare outline with a proximal articular facet that is larger than the distal facet. The middle proximal carpal, interpreted here as a centrale following Caldwell (1997), is distinctively broad and has two well-marked distal facets. The ulnare is larger than wide, with well-developed facets in the proximal end for the ulna and the postaxial ossicle. The distal carpal 1 and distal carpal $2+3$ (the middle distal carpal is here interpreted as a fusion of the distal carpals 2 and 3 , based on the arrangement of digits II and III) are preserved in both limbs: parts of the left elements are lost due to cracking, but these are intact in the right forelimb. This same extremity also shows a wellpreserved distal carpal 4, being larger and narrower than the other two distal carpals 1 and $2+3$, and with two proximal articular facets for the centrale and ulnare.

The proximal phalanges of the right forelimb remained articulated in a single block, whereas the distal-most elements are partially crushed together with two gastralia. The phalanges are spool-shaped and elongated distally with broad articular facets, but are softly compressed dorsoventrally. Digit I is complete in the right forelimb, bearing six phalanges.

\section{Hind Limb}

The hind limbs are known only by the right extremity, which is partially preserved. The proximal portion of the right femur is absent. Its ventral surface (Fig. 16A, B) bears several rugosities that are stronger on the dorsal surface. The diaphysis is observed in cross-section; it is compressed by compact bone and shows an oval contour and a dorsoventral compression of the bone, whereas the distal end is flattened and its posterior end significantly expanded. A small portion of the anterior margin is lost from the distal end, although three distal articular facets are present; two larger facets for the epipodials and a reduced posterior facet that might be for a supranumerary element (that is not preserved). A muscle attachment site and a fossa are located on the distal margin of the diaphysis. The epipodials (tibia and fibula) are preserved as fragments attached to the femur and to the following block. The available portions do not allow for an evaluation of their length, but their distal facets are preserved and show that the tibia is slightly wider than the fibula (Fig. 16A, B). There is a tiny postaxial ossicle articulated to the posterodistal margin of the fibula. The mesopodials are well preserved, with a tibiale of square outline. The centrale is slightly larger than the other mesopodials and more conservative in size than the equivalent element in the forelimb. The fibulare also has a square outline, with two proximal facets for the fibula and the postaxial ossicle, and is the smallest mesopodial element in the hind limb. The distal tarsals are well preserved in the same block. Distal tarsal 1 and distal tarsal $2+3$ are very similar in size and outline, whereas distal tarsal 4 is larger and narrower, with enlarged proximal facets for the fibulare and centrale. Metatarsal 5 is typically shifted into the distal tarsal row, whereas metatarsal 1 is robust and massive.

\section{Gastroliths}

Five elements interpreted as gastroliths were recovered from the blocks during preparation. These were scattered along the trunk, and their size varies from ca. $10 \mathrm{~mm}$ to over $70 \mathrm{~mm}$. A large number of gastroliths (560) have been previously recorded in a specimen of Aristonectes recovered from the upper Maastrichtian beds of Seymour Island, Antarctica (O'Gorman et al., 2012). 


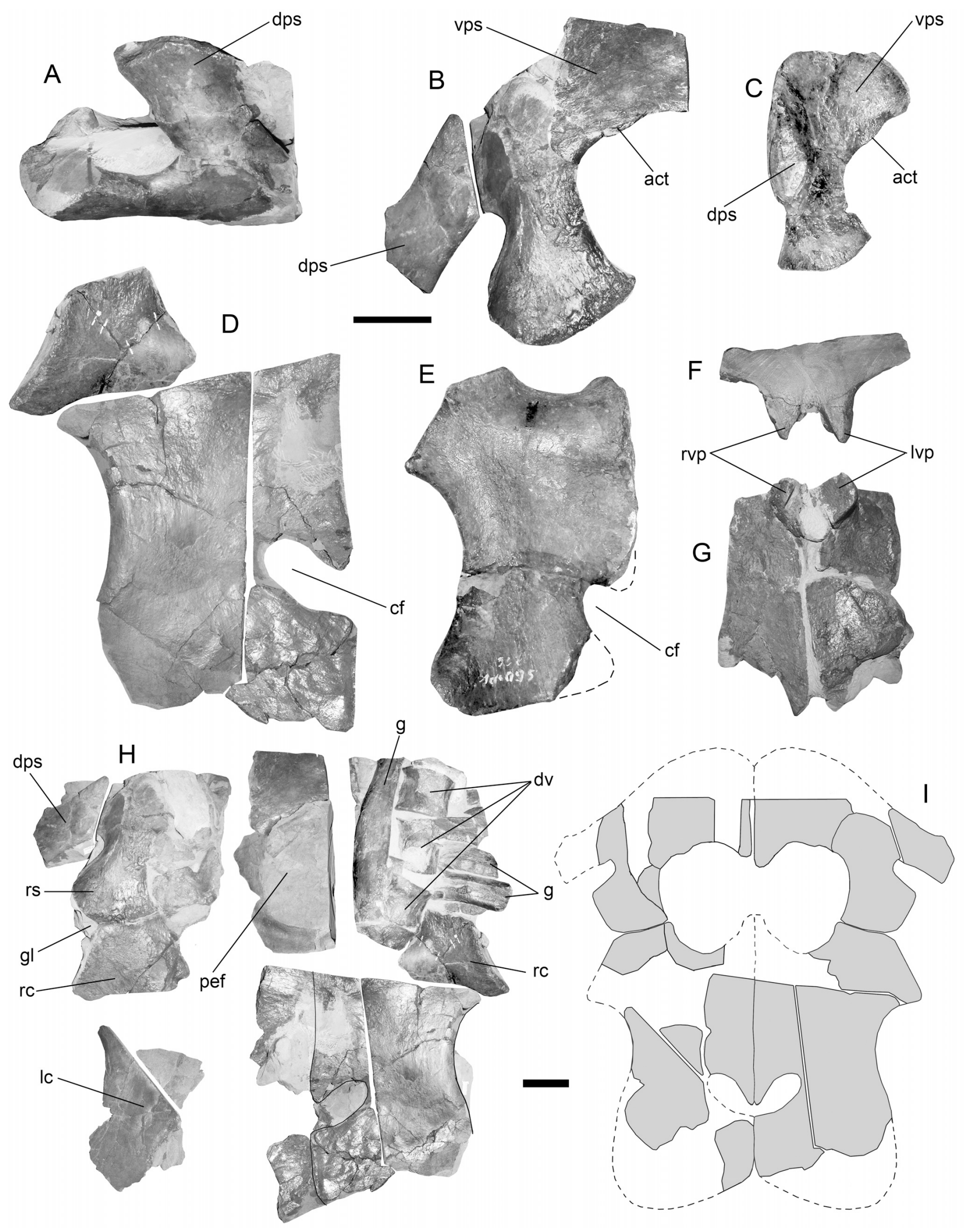


A
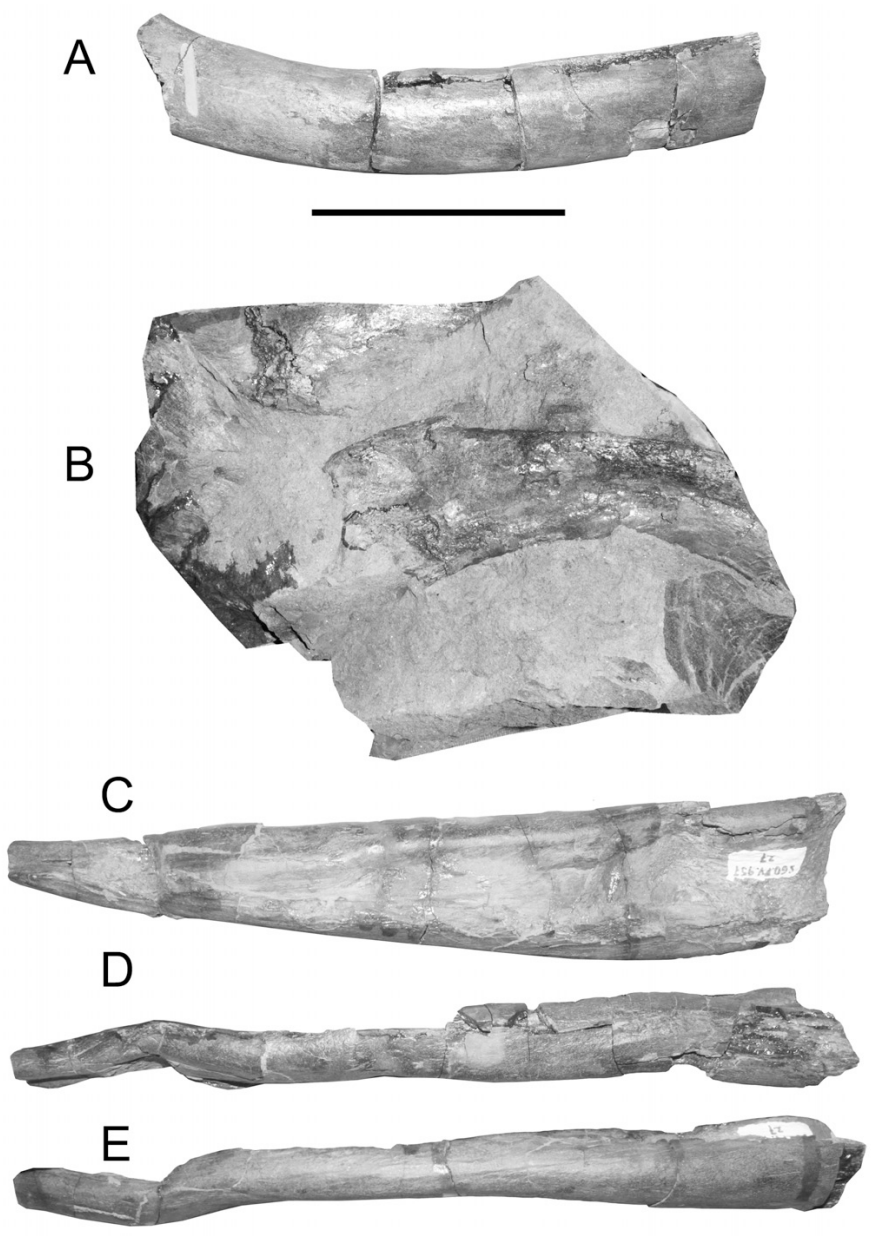

FIGURE 14. Aristonectes quiriquinensis, sp. nov. (SGO.PV.957, holotype). A, dorsolateral aspect of a representative dorsal rib; $\mathbf{B}$, dorsocervical cartilaginous ribs preserved in anatomical position on the dorsal side of the block that hosts the right dorsal scapular process; $\mathbf{C}$, representative pachyostothic gastralium crushed, in axial view; D, same in dorsal view; E, ventral view. Scale bar equals $100 \mathrm{~mm}$.

\section{PHYLOGENETIC ANALYSIS}

The morphological characters of the new specimen were included in a phylogenetic analysis based on the data set of O'Keefe and Street (2009), which originally returned Aristonectes and Kaiwhekea as related to cryptoclidoids. Nine taxa were added (Table 2) and five characters were modified (Table 3). The data set was analyzed using TNT version 1.1 (Goloboff et al., 2003) with Traditional Search (Wagner algorithm, 1000 replicates, TBR with 100 trees to save per replication). Bootstrap analysis was performed with 10,000 replicates (Poisson independent reweighting) for testing the stability of the tree. The data set is included in Appendix 1 (see Supplementary Data). Six most parsimonious trees were obtained (tree length $=254$ steps; retention index $=$ 0.68 ; consistency index $=0.52$ ). The specimen TTU.P.9219 ('Morturneria seymourensis') was not considered because of its juvenile condition and fragmentary nature, which prevents scoring of many characters. The strict consensus tree (Fig. 17) shows two main clades within Elasmosauridae (node 1), and groups all very-longnecked elasmosaurids in node 2 with partially unresolved internal relationships. In the latter node, $M$. haasti and $T$. keyesi formed a separate internal node together with Callawayasaurus colombiensis from the Aptian of Colombia. Node 3 groups all plesiosaurians previously included in Aristonectinae by Otero et al. (2012), as well as the new $A$. quiriquinensis holotype. F. suzuki appears as a basal member of Aristonectinae, whereas $K$. katiki is obtained as the sister taxon of Aristonectes spp. The most exclusive branch remains unresolved, including $A$. parvidens and the holotype and referred specimen of $A$. quiriquinensis. Bootstrap analysis returned support of $50 \%$ or more for two nodes within Elasmosauridae (Aristonectinae, and the Aristonectes node), whereas M. haasti (CM Zfr 115), C. colombiensis, and T. keyesi are grouped in a poorly supported branch. The hypotheses of relationships obtained in the strict consensus tree and the bootstrap result were integrated with the stratigraphic occurrence of each taxon (Fig. 17). The synapomorphic characters that group K. katiki and Aristonectes spp. are the common presence of a skull of 'primitive' length (skull length equivalent to the length between the atlas-axis complex and the tenth or eleventh anterior cervical); reduced neck length (compared with elasmosaurids from the Upper Cretaceous of the Northern Hemisphere); more than 25 maxillary teeth; and epipodials proximodistally longer than mediolaterally broad.

\section{DISCUSSION}

\section{Relationships with the Referred Specimen SGO.PV.260}

Specimen SGO.PV.260, referred to A. quiriquinensis, shares almost all postcranial characters with the holotype. In both, the posterior cervical vertebrae bear anteriorly angled neural spines with distinctive alternate lateral flanges (anterior to the left, posterior to the right). They also share the presence of cervical ribs that are angled anteriorly and lack posterior processes. These features were previously noted from the referred specimen by Otero et al. (2012:fig. 3D), but these authors were unable to discount the possibility that they were taphonomic artifacts because they are not fused to their respective centra. The orientation and shape of the cervical ribs in the holotype of $A$. quiriquinensis are consistent with those of the referred specimen, confirming that this feature is real, highly diagnostic (although it is yet unknown in A. parvidens), and that it is ontogenetically conservative. Also, the cervical ribs of both specimens are blade-like, slightly expanded distally, and have subcircular articular facets.

The features of the coracoids are interesting: in the holotype of A. quiriquinensis, the bone is well-ossified and can be traced by an outline that coincides with the coracoids observed in the referred

$\leftarrow$ FIGURE 13. Aristonectes quiriquinensis, sp. nov. A, right scapula in lateral view (SGO.PV.957); B, composite picture of the portions of the right scapula in ventral view (SGO.PV.957); C, left scapula in dorsal view (SGO.PV.260); D, composite picture of the portions of the right coracoid in dorsal view, mirrored for comparison (SGO.PV.957); E, left coracoids in dorsal view (SGO.PV.260); F, sagittal cross-section of the coracoid symphysis, showing the anterior view of the separate ventral processes, as well as the dorsal fusion of the coracoids (SGO.PV.957); G, ventral view of the same block, showing the separated ventral processes and symphysis (SGO.PV.957); H, general aspect of the preserved portions of the pectoral girdle (SGO.PV.957); I, dorsal outline of the pectoral girdle based on the preserved portions (SGO.PV.957). Scale bars equal $100 \mathrm{~mm}$. 


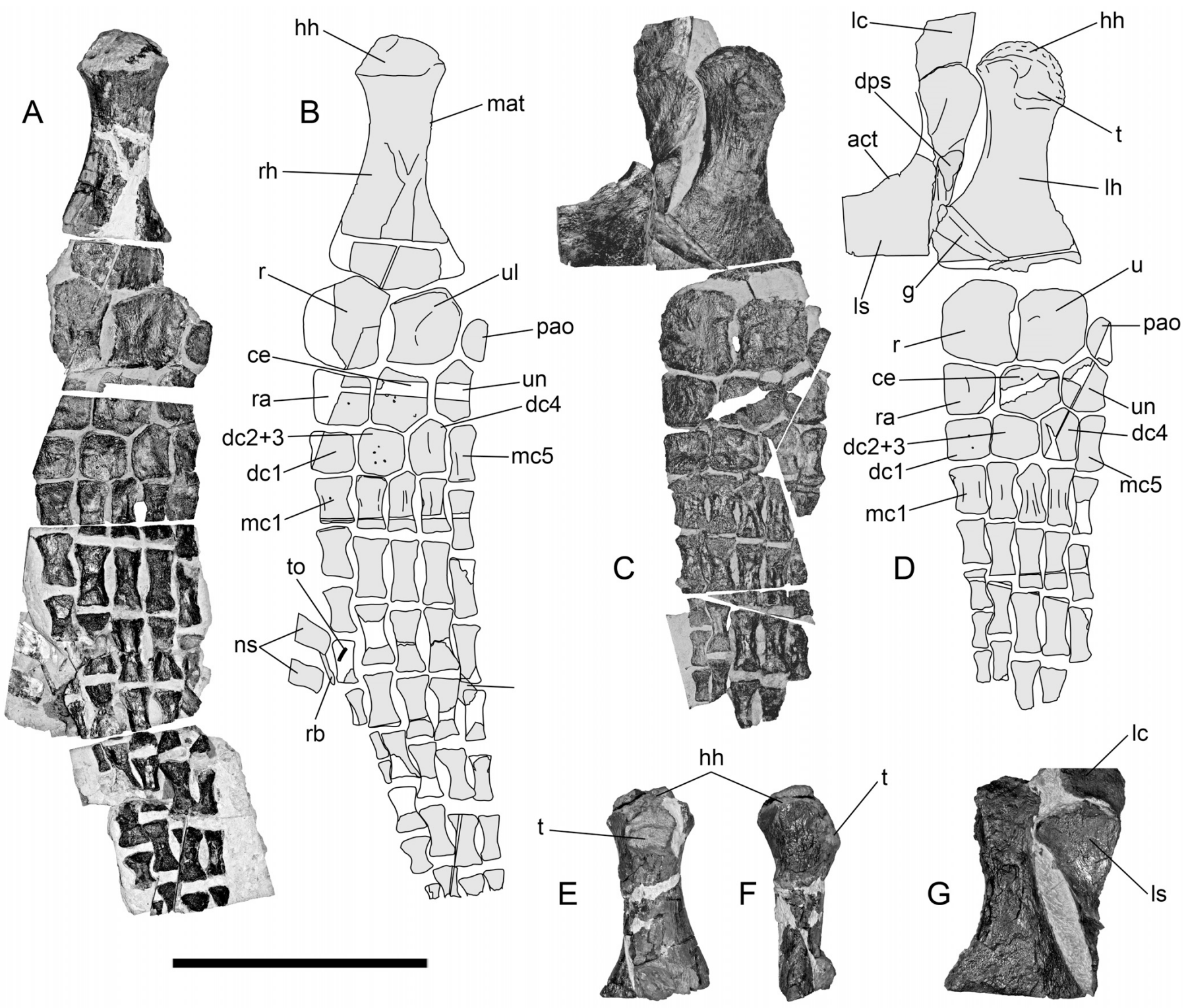

FIGURE 15. Aristonectes quiriquinensis, sp. nov. (SGO.PV.957, holotype). A, right forelimb in ventral view; B, outline of the elements preserved in the right forelimb; $\mathbf{C}$, left forelimb in dorsal view; $\mathbf{D}$, outline of the elements preserved in the left forelimb; $\mathbf{E}$, right humerus in dorsal view; $\mathbf{F}$, posterior view; G, left humerus in ventral view. Scale bar equals $500 \mathrm{~mm}$.

specimen (SGO.PV.260), whereas the posterior coracoidal enclosure is composed of thin and poorly ossified bone. Therefore, the coracoids of $A$. quiriquinensis are of elasmosaurid type. Other previously described elasmosaurids from the Southern Hemisphere bear a cordiform fenestra with a nearly closed posterior end in subadult specimens (Welles, 1962:fig. 23; Carpenter, 1999:fig. 6; Hiller and Mannering, 2005:fig. 8), indicating that depending on ontogeny, this feature may represent a common condition in older individuals of the group.

One of the most remarkable differences between $A$. quiriquinensis and other elasmosaurids is present in the pectoral girdle, but can only be compared with Wapuskanectes betsynichollsae (Druckenmiller and Russell, 2006). It shows similar coracoids with posterior symphyseal rejoining, leaving an intercoracoidal (cordiform) vacuity. The presence of a fully open cordiform fenestra between the coracoids is considered diagnostic for elasmosaurids (Welles, 1962; O'Keefe, 2001; Gasparini et al., 2003a; Druckenmiller and Russell, 2008), and in this sense, the referred specimen SGO.PV.260 adds valuable information. In this specimen, although the posteromedial portion is incomplete, a fully open cordiform fenestra is likely to be present, which confirms that the posterior closure of the coracoids is a secondary feature expressed in comparatively older individuals. The presence of an open cordiform fenestra was also recorded in a juvenile specimen referred to Aristonectes from the upper Maastrichtian of Antarctica (O'Gorman et al., 2013). 


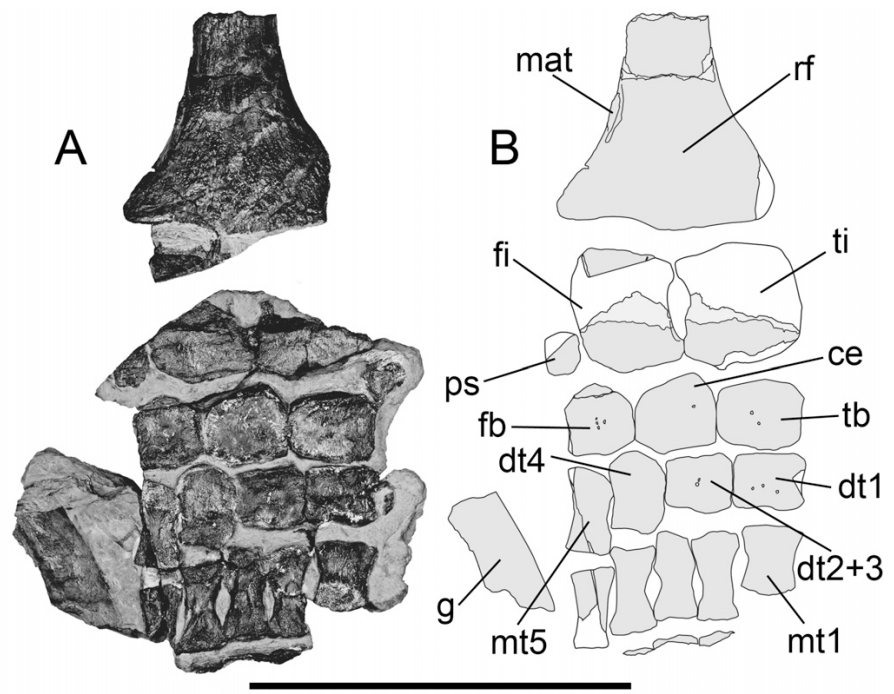

FIGURE 16. Aristonectes quiriquinensis, sp. nov. (SGO.PV.957, holotype). A, preserved portion of the right hind limb in dorsal view; $\mathbf{B}$, outline of the preserved elements. Scale bar equals $500 \mathrm{~mm}$.

In the referred specimen of $A$. quiriquinensis, the scapulae appear to be elements without symphyseal contact, whereas in the holotype they show a clear midline symphysis without fusion. This difference is here explained by ontogeny. A similar contact without fusion is also observed in immature individuals of Cryptoclidus oxoniensis (Andrews, 1910:figs. 88, 89). Also, the presence of the acromion process in the anterior margin of the pectoral fenestra is a morphology observed in both the holotype and the referred specimen. This small bony lamina projects in posterior direction from the fenestral margin of the scapulae (Fig. 9I).

The humeral head is conservative ontogenetically, having a distinctive diameter larger than that of the diaphysis. The head becomes hemispherical during growth, at least on the basis of the two specimens studied here. The femur is also conservative through ontogeny, although in the holotype (SGO.PV.957) this bone bears a well-developed posterior muscle attachment site that is not evident in the referred specimen (SGO.PV.260). The phalanges of both the fore- and hind limbs have conservative proportions, being gracile and elongate even in the younger stage; nevertheless, they appear to be much larger in the nearly adult specimen.

The common features of the humerus in the holotype and referred specimen include a distal transverse cross-section that is bi- convex with a slightly flatter dorsal surface, with a posterior extension leading to a hydrodynamic profile, but its distal portion seems to be more compressed in the holotype (but slight crushing cannot be discounted). The humeral head is very similar in both specimens. Its articular surface is convex but not hemispherical, and slightly larger than the diameter of the diaphysis. The only noticeable difference is the presence of a larger tuberosity in SGO.PV.957, which is explained by different ontogenetic stages. The epipodials, as well as the proximal and distal mesopodials, are coincident in the holotype and the referred specimen. The radius and ulna are lunate in both specimens; the mesopodials are similar, although the centrale is broader in the holotype, which can be explained by allometry during the ontogeny. Also, the fused distal carpals $2+3$ are present in both specimens.

The distal end of the femur is also conservative through ontogeny, although in the holotype (SGO.PV.957), this bone bears a well-developed posterior muscle attachment site that is not observable in the referred specimen (SGO.PV.260). The hind limb elements of the holotype are hard to compare with the referred specimen, because no complete epipodials are known in the former and scarce mesopodials are recognized in the latter. The elements referred to as the fibula and fibulare by Otero et al. (2012:fig.10D) are here maintained, being partially scattered and slightly differing in shape due the lack of well-defined facets because of the juvenile stage of the specimen. The presence of a postaxial ossicle in the holotype is confirmed in the referred specimen, being more circular in the latter (Otero et al., 2012:fig.10D). The phalanges of both fore- and hind limbs have conservative proportions, being gracile and elongate even in the younger stage; nevertheless, they appear to be much larger in the nearly adult specimen.

Finally, the referred specimen (SGO.PV.260) verifies the presence of octagonal anterior caudals in A. quiriquinensis. These distinctive centra (Fig. 18A, B) were originally described by Cabrera (1941) as cervicals of $A$. parvidens, and later reidentified by Gasparini et al. (2003a) as caudals. Otero et al. (2012) described and referred to them as sacrals, although the taxonomic determination of the specimen SGO.PV.260 then restricted it to the subfamily Aristonectinae. With the new evidence here presented, these octagonal anterior caudals can be considered as an autapomorphy of the genus Aristonectes.

\section{Observations on Previously Known Extremities of Aristonectes}

The well-articulated forelimbs of the holotype of $A$. quiriquinensis clarify uncertainties in the previously identified anatomical elements of the limbs of the referred specimen. In the latter, the best-preserved paddle is separated from its respective propodial, and two limbs are preserved as articulated phalanges only, whereas epipodial/mesopodial elements are

TABLE 2. Sources of information for the taxa added to the data matrix of O'Keefe and Street (2009), used for phylogenetic analysis of the studied material.

\begin{tabular}{|c|c|c|}
\hline Taxon & Specimen & References \\
\hline Aristonectes parvidens & Holotype & Cabrera (1941); Gasparini et al. (2003b) \\
\hline Callawayasaurus colombiensis & Holotype & Welles (1962); Carpenter (1999) \\
\hline Futabasaurus suzukii & Holotype & Sato et al. (2006) \\
\hline Hydrotherosaurus alexandrae & Holotype & Welles $(1943,1952)$ \\
\hline Kaiwhekea katiki & Holotype & Cruickshank and Fordyce (2002) \\
\hline Mauisaurus haasti & $\begin{array}{l}\text { Most complete } \\
\text { Referred specimen }\end{array}$ & Hiller et al. (2005) \\
\hline Microcleidus tournemirensis & Holotype & Bardet et al. (1999); Benson et al. (2012) \\
\hline Styxosaurus snowii & Holotype & Welles $(1943,1952,1962)$; Carpenter (1999) \\
\hline Thalassomedon haningtoni & Holotype & Welles $(1943,1952,1962)$; Carpenter $(1997,1999)$ \\
\hline Tuarangisaurus keyesi & Holotype & Wiffen and Moisley (1986); Carpenter $(1997,1999)$ \\
\hline
\end{tabular}


TABLE 3. List of modifications to the data set of O'Keefe and Street (2009).

\begin{tabular}{|c|c|c|}
\hline Character (O'Keefe and Street, 2009) & Number & Modifications \\
\hline $\begin{array}{l}\text { Posterior articulation for succeeding neural spine, } \\
\text { cervical vertebrae }\end{array}$ & 57 & new state (2); present but disposed laterally to the right \\
\hline Anterior process of the cervical ribs & 59 & new state (2); without anterior process but strongly recurved anteriorly \\
\hline Anterior neural flange on vertical neural spine & 60 & new state (2); present, but disposed laterally to the left \\
\hline Neural spines, cervical vertebrae & 61 & new state (2); angled rostrally \\
\hline
\end{tabular}

scattered in several blocks of the trunk. Only the right hind limb remains in anatomical position, although partially disarticulated and obscured by the trunk. An evaluation of the position of each paddle is therefore difficult. Based on the larger sizes of phalanges in two blocks, Otero et al. (2012:fig. 10) attributed these to the forelimbs, whereas more gracile, narrower phalanges were referred to the hind limb. The presence of a lunate radius and ulna together with the more gracile and elongate phalanges in the holotype of $A$. quiriquinensis indicates that the more gracile paddles are the forelimbs. This is the reverse of the usual elasmosaurid pattern of larger forelimbs (O'Keefe, 2002).

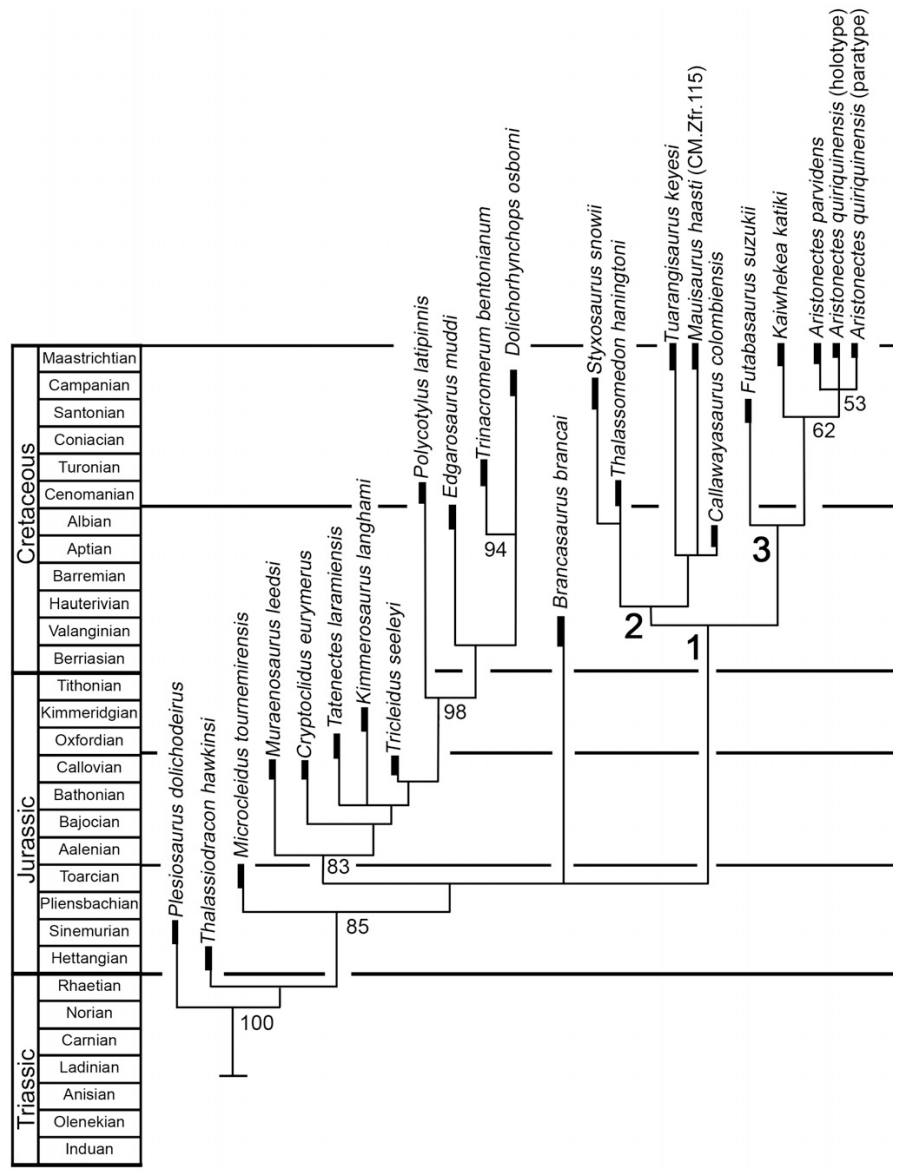

FIGURE 17. Strict consensus tree (tree length $=254$ steps; retention index $=0.68$; consistency index $=0.52$ ) of 24 plesiosaur taxa including their stratigraphic occurrences. Resampling indexes (bootstrap $=10,000$ replicates) higher than $50 \%$ are indicated under branches. Bold branches represent known biochrons of each taxon. Positions of nodes are not timecalibrated.

\section{Autapomorphic Characters of Aristonectes quiriquinensis, sp. nov.}

Comparisons with A. parvidens-Most of the new morphological features observed in the holotype of $A$. quiriquinensis are in anatomical regions that are currently unknown in $A$. parvidens. In consequence, several of the new characters should be treated as potentially apomorphic until more complete specimens of $A$. parvidens are found. However, a taxon within Aristonectes but different from $A$. parvidens is justified based on differences in the skull and the cervical vertebrae. Unique skull characters in the holotype of $A$. quiriquinensis include the presence of a mental boss, a feature not observed in the holotype of $A$. parvidens. The symphyseal contact of the dentaries in A. quiriquinensis is comparatively thicker and lacks the deep groove observed in ventral view in $A$. parvidens, (Gasparini et al., 2003a:fig. 2B). In lateral view, the symphysis of $A$. quiriquinensis is narrower than that of $A$. parvidens, although both have a slight constriction in each ramus posterior to the premaxillary-maxillary suture. Another noticeable difference is the presence of several large, labial foramina in the mandible of $A$. quiriquinensis; these are not present in the holotype of $A$. parvidens. Also, the posterior-most teeth of $A$. parvidens are about $60 \mathrm{~mm}$ rostral to the coronoid process. In A. quiriquinensis, there are no alveoli even though $130 \mathrm{~mm}$ of mandible is preserved rostral to the coronoid process. In consequence, it is likely that $A$. quiriquinensis had many fewer teeth than $A$. parvidens. Other differences are observed in the lingual and labial surfaces of the posterior portion of each ramus. In $A$. parvidens, the labial contact between the angular and surangular (anterior to the glenoid fossa) bears a deep excavation that is not present in $A$. quiriquinensis. Finally, the portion of the retroarticular process preserved in the right ramus of $A$. parvidens has a sharp dorsal keel, unlike the smooth and rounded surface of $A$. quiriquinensis.

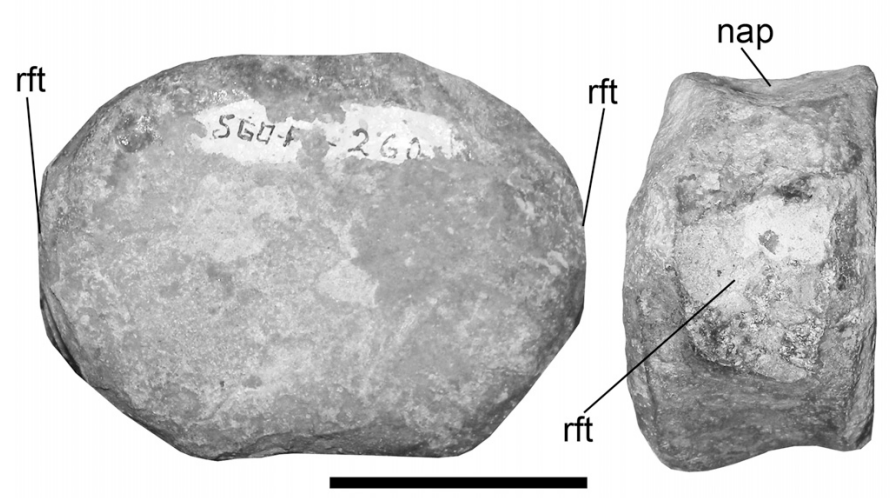

FIGURE 18. Aristonectes quiriquinensis, sp. nov. Representative anterior caudal centrum of the referred specimen (SGO.PV.260), showing the distinctive octagonal articular outline. A, anterior view; $\mathbf{B}$, left lateral view. Scale bar equals $50 \mathrm{~mm}$. 


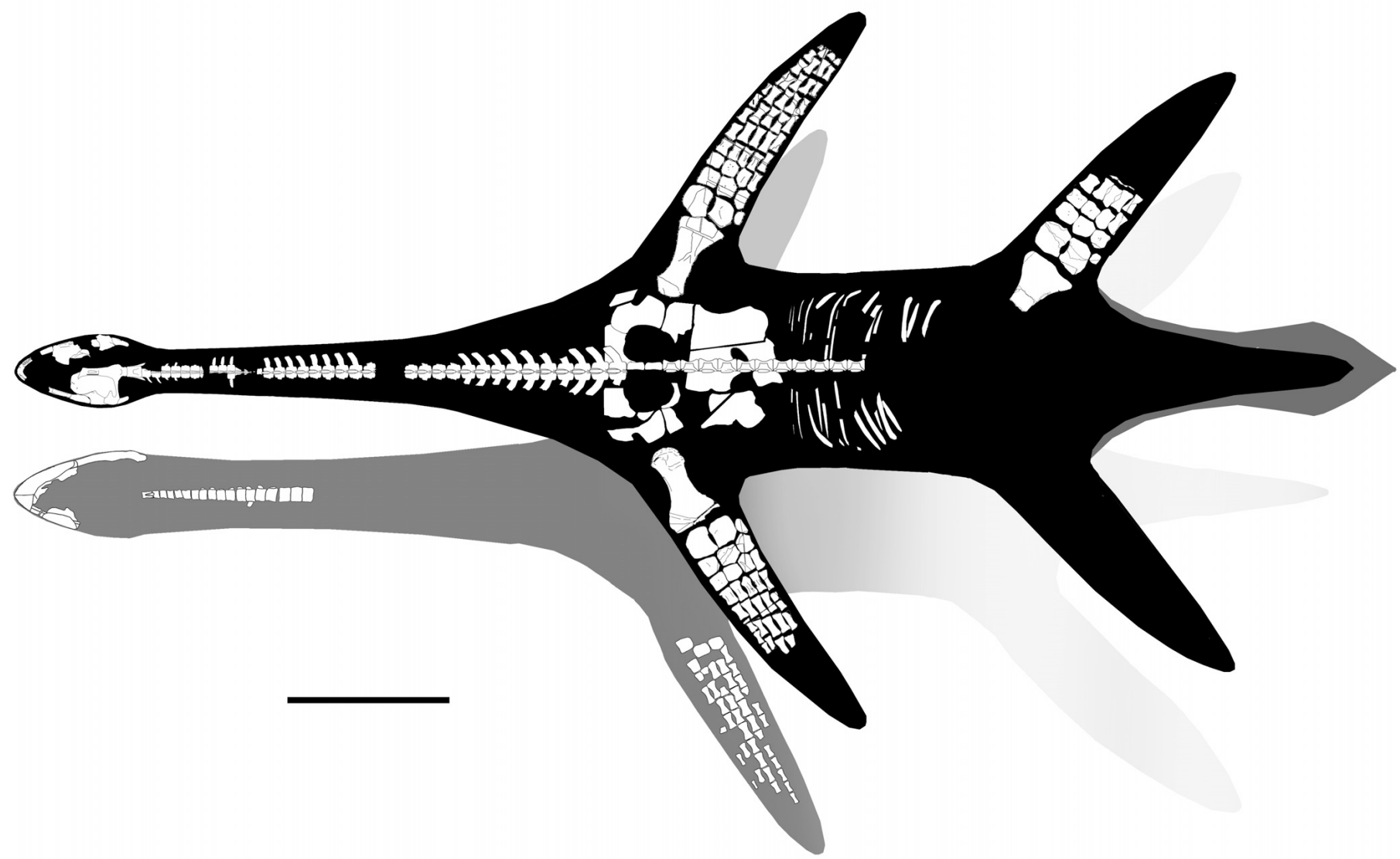

FIGURE 19. Reconstructed outline of Aristonectes quiriquinensis, sp. nov., based on the portions preserved in the holotype. The holotype of Aristonectes parvidens is included in grey outline, excluding the caudal centra due their uncertain anatomical position along the skeleton. Scale bar equals $1 \mathrm{~m}$.

A remarkable difference between the two taxa exists regarding the proportions of the skull and vertebrae. Between the tip of the premaxilla and the mandibular articulation, the skull of $A$. parvidens reaches $73.5 \mathrm{~cm}$ (Gasparini et al., 2003a), slightly longer than the $65-70 \mathrm{~cm}$ estimated for A. quiriquinensis. However, vertebral centra in the latter species are proportionally larger, broader, and higher than those in the holotype of $A$. parvidens, suggesting that it was a larger-headed taxon. The proportions of the skull and cervical vertebrae in A. quiriquinensis are more conservative and resemble other aristonectines such as $K$. katiki, which has a skull length of $62 \mathrm{~cm}$.

Regarding the postcranium, A. quiriquinensis is characterized by an atlas-axis complex in which the rib is formed by equal participation of the posterior projections of the atlas centrum and the intercentrum, whereas in $A$. parvidens the intercentrum does not have this process. According to Cabrera (1941), the anterior cervical ribs are recurved in $A$. parvidens and fused distally, whereas the cervical ribs in $A$. quiriquinensis are short and lack contacts. Unfortunately, these parts of the skeleton are now missing from the holotype of $A$. parvidens and cannot be directly compared. In addition, the juvenile referred specimen, SGO.PV.260, verifies the presence of blade-like, distally expanded cervical ribs throughout the middle and posterior portions of the neck in $A$. quiriquinensis (Otero et al., 2012:figs. 3C, D).

Comparisons with 'Morturneria seymourensis'-TTU P 9219, from the upper Maastrichtian of Antarctica. is the holotype of
'Turneria seymourensis' (Chatterjee and Small, 1989) (= 'Morturneria' seymourensis Chatterjee and Creisler, 1994) and later redesignated a junior synonym of $A$. parvidens by Gasparini et al. (2003a). Preservation and the ontogenetic stage of the specimen make a differential diagnosis with $A$. quiriquinensis difficult, although morphological differences are evident in the outlines of the sutures in the atlas-axis, and the height of the neural canal in middle cervical vertebrae (Chatterjee and Small, 1989:fig. 10A-C).

Comparisons with Skull Material CM Zfr 73 and CM Zfr 91 from New Zealand-Skull remains from the early Maastrichtian beds of the Conway Formation, exposed along the Waipara River, New Zealand, were described by Hiller and Mannering (2004). The material was considered as two separate specimens (CM Zfr 73 and CM Zfr 91), although they are similar in size, share a consistent deformation pattern, are anatomically complementary, and were collected at the same locality, therefore suggesting that they represent a single individual. Considering them as composite material, they have similar deformation to the holotype of $A$. quiriquinensis. Morphologically, both share the presence of a basioccipital with straight lateral margins (contrary to the anteroposterior constriction between the occipital condyle and the lateral margin of the basioccipital in 'Morturneria seymourensis'). The New Zealand material and $A$. quiriquinensis both also possess a foramen magnum that is dorsoventrally low; a supraoccipital with a large foramen (here interpreted as the posterior vertical semicircular canal); a paroccipital process with a robust proximal portion; 
a hemispherical occipital condyle that is dorsally flattened with a ventral encircling groove; and a squamosal covering the posterior portion of the temporal fossa in a similar way; and the shape and length of their retroarticular processes are almost identical. All of these facts strongly suggest that CM Zfr 73 and CM Zfr 91 belong to a still indeterminate aristonectine. Because the ontogenetic stage of the material from New Zealand was regarded as an old adult (Hiller and Mannering, 2004), the specific affinities of this taxon should be evaluated due their evident smaller adult size as compared with A. quiriquinensis.

\section{Regarding the General Aspect of Aristonectes quiriquinensis, sp. nov.}

The skeleton described herein allows verification of the observation of Cabrera (1941), who suggested that the number of cervical vertebrae in Aristonectes could be near 30. The holotype of A. quiriquinensis preserves 37 cervicals (including the atlas-axis), 12 of which are from the anterior portion and 23 from the middleposterior series. In addition, the referred specimen preserves 23 vertebrae from the neck (or 24 based on available neural spines). It is likely that two or three vertebrae are lost from the holotype of $A$. quiriquinensis due to erosion, indicating that the total number of cervical vertebrae may have been 40-42, similar to the 43 cervicals described by Cruickshank and Fordyce (2002) for $K$. katiki. Based on this observation, and considering the average length of the cervical vertebrae available, neck length can be estimated as roughly $3.0-3.5 \mathrm{~m}$, and, together with the skull, reaching $>4.2 \mathrm{~m}$. The number of dorsal centra in the referred specimen is about 20; considering the average length of the dorsal centra preserved in the holotype, this indicates an estimated length of $2 \mathrm{~m}$ for the dorsal series. Based on the caudal region of the referred specimen, we estimate the total length of the holotype as approximately $9 \mathrm{~m}$.

In articular view, the cervical ribs and neural spines of the posterior-most cervicals of the holotype are separated by an angle of approximately $145^{\circ}$, and the length of each cervical rib almost equals the height of the neural spine (in the referred specimen, ribs are slightly shorter). This indicates that the neck was high but laterally compressed. The width between the glenoids in the pectoral girdle is about $0.86 \mathrm{~m}$, whereas the gastralia are short and numerous. The high number of gastralia and ribs in the referred specimen indicates a gracile and slender trunk. The unusually high aspect ratio of the flippers also adds to the gracile aspect, which likely had recurved and compressed extremities. A tentative outline based on known bony elements is presented in Figure 19.

A. quiriquinensis has several morphological characteristics also found in cryptoclidids, including the presence of a long, but comparatively shorter neck with 35-40 vertebrae; a skull larger than those of typical elasmosaurids from the Northern Hemisphere and that is more similar in proportions to that of Cryptoclidus; a high number of maxillary and dentary teeth, as in Kimmerosaurus (Brown, 1981); more than five premaxillary teeth; pachyostosis limited to the gastralia only, as in Tatenectes laramiensis (O'Keefe and Street, 2009; O'Keefe et al., 2011); and anterodorsally directed neural spines (O'Keefe et al., 2011). Other features are only present in elasmosaurids, such as the presence of posterior interpterygoid vacuities with the anterior portion of the parasphenoid enclosed by the pterygoids; an occipital condyle composed only of the basioccipital; bilobed cervical vertebrae; and the open cordiform fenestra in the coracoids. The ontogeny of A. quiriquinensis indicates that this species is an unusual elasmosaurid with a 'cryptocleidoid-like' phenotype. The general aspect of A. quiriquinensis is a remarkable case of convergence be- tween two lineages with a wide stratigraphic gap that extends from Upper Jurassic to Maastrichtian times.

\section{CONCLUSIONS}

The new skeleton described here from upper Maastrichtian sediments of the Quiriquina Formation in central Chile is a young adult individual of Aristonectes. Several new morphological features are identified for the mandible, atlas-axis, cervical neural spines, cervical ribs, and skull/cervical vertebrae proportions, as well as for the fore- and hind limbs. They are unrelated to ontogenetic differences when compared with the holotype of $A$. parvidens, and thus justify the erection of a new species, Aristonectes quiriquinensis. A second referred specimen comprises a largely complete postcranial skeleton of a young individual previously found in the Quiriquina Formation from its type locality on Quiriquina Island. This specimen preserves other features and allows for the recognition of skeletal changes during ontogeny. One of the most relevant morphological features is the presence of a coracoid with a fully open cordiform fenestra in the juvenile, but that is secondarily closed in the young adult. The coracoids are also characterized by a prominent conical ventral process. These new features, along with the bilobed middle cervical vertebrae and the presence of posterior interpterygoid vacuities with the anterior portion of the parasphenoid enclosed by the pterygoids, are diagnostic characters that demonstrate that Aristonectes is an elasmosaurid plesiosaur. The primitive skull size and neck length, increased number of vertebrae, anteriorly directed neural spines, and a coracoid symphysis with posterior contact closely resemble Jurassic cryptoclidoids. A. quiriquinensis is the youngest known species of plesiosaur described to date and one of the last representatives of this group prior to their extinction near the Cretaceous-Paleogene boundary.

Based on phylogenetic analysis, Futabasaurus suzuki, from the Santonian of Japan, might represent the basal-most member of Aristonectinae, having an intermediate morphology between the latter group and the very-long-necked elasmosaurids typical of the Northern Hemisphere and (less frequently) in the Upper Cretaceous of the South Pacific. The proposal of a second species of Aristonectes in the Pacific realm encourages future work to further distinguish the specific affinities of other related specimens, especially those from Antarctica.

\section{ACKNOWLEDGMENTS}

D. Rubilar-Rogers, R. A. Otero, and S. Soto-Acuña are supported by the Antarctic Ring Project (Anillos de Ciencia Antártica ACT-105, Conicyt-Chile). F. R. O'Keefe was supported by funds from the Marshall University Department of Biological Sciences, College of Science, and a John Deever Drinko Research Fellowship. W. Stinnesbeck gratefully acknowledges support by the Deutsche Forschungsgemeinschaft (grant STI 128/20-1). Special acknowledgments go to M. Reguero and Z. Gasparini (Universidad de La Plata, Argentina) for the access to the holotype of A. parvidens and the good will and help provided. P. Druckenmiller and R. Benson are gratefully acknowledged for their critical reviews of the manuscript and the very valuable comments that helped to improve it. Field work at Cocholgüe was executed in March 2009 by a student group of the Departamento de Geociencias of the Universidad de Concepción, headed by A. QuinzioSinn and C. Salazar. K. E. Buldrini, J. Alarcón (Laboratorio de Zoología de Vertebrados, Facultad de Ciencias, Universidad de Chile), and D. Delgado (Universidad CES y Escuela de Ingeniería de Antioquia, Colombia) are acknowledged for their excellent work on the preparation of the specimen. 


\section{LITERATURE CITED}

Andrews, C. W. 1910. A Descriptive Catalogue of the Marine Reptiles of the Oxford Clay, Part I. British Museum (Natural History), London, $205 \mathrm{pp}$.

Bardet, N., P. Godefroit, and J. Sciau. 1999. A new elasmosaurid plesiosaur from the Lower Jurassic of southern France. Palaeontology 42:927-952.

Benson R. B. J., M. Evans, and P. S. Druckenmiller. 2012. High diversity, low disparity and small body size in plesiosaurs (Reptilia, Sauropterygia) from the Triassic-Jurassic boundary. PLoS ONE 7:e31838. doi: 10.1371/journal.pone.0031838.

Biró-Bagóczky, L. 1982. Revisión y redefinición de los 'Estratos de Quiriquina', Campaniano-Maastrichtiano, en su localidad tipo, en la Isla Quiriquina, $36^{\circ} 37^{\prime}$ Lat. Sur, Chile, Sudamérica, con un perfil complementario en Cocholgüe. Congreso Geológico Chileno No 3, November 6-14, 1982, Concepción, Chile, Actas 1:A29A64.

Blainville, H. M. D. de 1835. Description de quelques espèces de reptiles de la Californie précédé de l'analyse d'un système général d'herpétologie et d'amphibiologie. Nouvelles Annales du Muséum d'Histoire Naturelle de Paris, Série 3 4:233-296.

Broili, F. 1930. Plesiosaurierreste von der Insel Quiriquina. Neues Jahrbuch für Mineralogie, Geologie und Paläontologie Beilage-Band (B) 63:497-514

Brown, D. S. 1981. The English Late Jurassic Plesiosauroidea (Reptilia) and a review of the phylogeny and classification of the Plesiosauria. Bulletin of the British Museum (Natural History), Geology 4:225-234.

Cabrera, A. 1941. Un Plesiosaurio nuevo del Cretáceo del Chubut. Revista del Museo de La Plata 2:113-130.

Caldwell, M. 1997. Limb osteology and ossification patterns in Cryptoclidus (Reptilia: Plesiosauroidea) with a review of sauropterygian limbs. Journal of Vertebrate Paleontology 17:295-307.

Caldwell, M. W. 2002. From fins to limbs to fins: limb evolution in fossil marine reptiles. American Journal of Medical Genetics 112:236249.

Carpenter, K. 1997. Comparative cranial anatomy of two North American Cretaceous plesiosaurs; pp. 191-216 in J. M. Callaway and E. L. Nicholls (eds.), Ancient Marine Reptiles. Academic Press, San Diego.

Carpenter, K. 1999. Revision of North American elasmosaurs from the Cretaceous of the Western Interior. Paludicola 2:148-173.

Carroll, R. L. 1969. A middle Pennsylvanian captorhinomorph, and the interrelationships of primitive reptiles. Journal of Paleontology 43:151-170.

Carroll, R. L. 1981. Plesiosaur ancestors from the Upper Permian of Madagascar. Philosophical Transactions of the Royal Society of London, Series B 293:315-383.

Carroll, R. L. 1988. Vertebrate Paleontology and Evolution. W. H. Freeman, New York, 698 pp.

Casamiquela, R. 1969. La presencia en Chile del género Aristonectes Cabrera (Plesiosauria), del Maestrichtiense del Chubut, Argentina. Edad y carácter de la transgresión 'Rocaense'. Jornadas Geológicas Argentinas No 4, April 6-16, 1969, Mendoza, Argentina, Actas 1:199-213.

Chatterjee, S., and B. S. Creisler. 1994. Alwalkeria (Theropoda) and Morturneria (Plesiosauria), new names for preoccupied Walkeria Chatterjee, 1987 and Turneria Chatterjee and Small, 1989. Journal of Vertebrate Paleontology 14:142.

Chatterjee, S., and B. J. Small. 1989. New plesiosaurs from the Upper Cretaceous of Antarctica; pp. 197-215 in J. M. Crame (ed.), Origins and Evolution of the Antarctic Biota. Geological Society of London Special Publication 47

Cecioni, G. 1955. Distribuzione verticale di alcune Kossmaticeratidae della Patagonia cilena. Bolettino de la Societá Geológica Italiana 74:141-148.

Cope, E. D. 1869. Synopsis of the extinct Batrachia, Reptilia and Aves of North America. Transactions of the American Philosophical Society, New Series 14:1-252.

Cruickshank, A. R., and R. E. Fordyce. 2002. A new marine reptile (Sauropterygia) from New Zealand: further evidence for a Late Cretaceous austral radiation of cryptocleidid plesiosaurs. Palaeontology 45:557-575.
Druckenmiller, P. S., and A. P. Russell. 2006. A new elasmosaurid plesiosaur (Reptilia: Sauropterygia) from the Lower Cretaceous Clearwater Formation, northeastern Alberta, Canada. Paludicola 5:184-199.

Druckenmiller, P. S., and A. P. Russell. 2008. A phylogeny of Plesiosauria (Sauropterygia) and its bearing on the systematic status of Leptocleidus Andrews, 1922. Zootaxa 1863:1-120.

Fuenzalida, H. 1956. Los saurios de la Isla Quiriquina. Noticiario Mensual del Museo Nacional de Historia Natural (Santiago) I(5):1.

Gasparini, Z. 1979. Comentarios críticos sobre los vertebrados mesozoicos de Chile; pp. H15-H32 in Congreso Geológico Chileno No. 2, Actas 3. August 6-11, 1979

Gasparini, Z., and L. Biró-Bagoczky. 1986. Osteopygis sp. (Reptilia, Testudines, Toxochelyidae). Tortuga Fósil de la Formación Quiriquina, Cretácico Superior, Sur de Chile. Revista Geológica de Chile, Nota Paleontológica 27:85-90.

Gasparini, Z., L. Salgado, and S. Casadío. 2003b. Maastrichtian plesiosaurs from northern Patagonia. Cretaceous Research 24:157-170.

Gasparini, Z., N. Bardet, J. E. Martin, and M. Fernandez. 2003a. The elasmosaurid plesiosaur Aristonectes Cabrera from the latest Cretaceous of South America and Antarctica. Journal of Vertebrate Paleontology 23:104-115.

Gay, C. 1847. Historia Física y Política de Chile. Zoología, Tomo Primero. Imprenta Maulde y Renou, Paris, $495 \mathrm{pp}$.

Gay, C. 1848. Historia Física y Política de Chile. Zoología, Tomo Segundo. Imprenta Maulde y Renou, Paris, $371 \mathrm{pp}$.

Gay, C. 1854. Historia Física y Política de Chile. Zoología 3-4. Imprenta Maulde y Renou, Paris, 186 pp.

Goloboff, P., J. Farris, and K. Nixon. 2003. T.N.T.: Tree Analysis Using New Technology. Program and documentation. Available at www.zmuc.dk/public/phylogeny. Accessed July 11, 2008.

Hector, J. 1874. On the fossil reptiles of New Zealand. Transactions of the New Zealand Institute 6:333-358.

Hiller, N., and A. Mannering. 2004. Elasmosaur (Reptilia: Plesiosauria) skull remains from the Upper Cretaceous of North Canterbury. New Zealand. Records of the Canterbury Museum 18:1-7.

Hiller, N., and A. Mannering. 2005. An unusual new elasmosaurid plesiosaur (Sauropterygia) from the Upper Haumurian (Maastrichtian) of the South Island, New Zealand. Memoirs of the Queensland Museum 51:27-37.

Hiller, N., A. Mannering, C. Jones, and A. Cruickshank. 2005. The nature of Mauisaurus haasti Hector, 1874 (Reptilia: Plesiosauria). Journal of Vertebrate Paleontology 25:588-601.

Jiménez-Huidobro, P., R. A. Otero, and D. Rubilar-Rogers. 2010. First evidence of a tylosaurine mosasaur from Chile. Journal of Vertebrate Paleontology, Program and Abstracts 2010:112A.

Kear, B. P. 2005. A new elasmosaurid plesiosaur from the Lower Cretaceous of Queensland, Australia. Journal of Vertebrate Paleontology 25:792-805

Kear, B. P. 2007. Taxonomic clarification of the Australian elasmosaurid genus Eromangasaurus, with reference to other austral elasmosaur taxa. Journal of Vertebrate Paleontology 27:241-246.

Ketchum, H. F., and R. B. J. Benson. 2010. Global interrelationships of Plesiosauria (Reptilia, Sauropterygia) and the pivotal role of taxon sampling in determining the outcome of phylogenetic analyses. Biological Reviews 85:361-392.

Ketchum, H. F., and R. B. J. Benson. 2011a. A new pliosaurid (Sauropterygia, Plesiosauria) from the Oxford Clay Formation (Middle Jurassic, Callovian) of England: evidence for a gracile, longirostrine grade of early Middle Jurassic pliosaurids. Special Papers in Palaeontology 89:109-129.

Ketchum, H. F., and R. B. J. Benson. 2011b. The cranial anatomy and taxonomy of Peloneustes philarchus (Sauropterygia, Pliosauridae) from the Peterborough Member (Callovian, Middle Jurassic) of the United Kingdom. Palaeontology 54:639-665.

Lambrecht, K., 1929. Neogaeornis wetzeli n. g. n. sp., der erste Kreidevogel der südlichen Hemisphäre. Paläontogische Zeitschrift 11:121129.

O'Gorman, J. P., Z. Gasparini, and M. Reguero. 2010. Aristonectes parvidens Cabrera (Sauropterygia, Plesiosauria) from Cape Lamb, Vega Island (Upper Cretaceous), Antarctica. XXXI Scientific Committee on Antarctic Research (SCAR) Open Science Conference, August 3-6, 2010, Buenos Aires, abstract 557. 
O'Gorman, J. P., Z. Gasparini, and L. Salgado. 2013. Postcranial morphology of Aristonectes Cabrera, 1941 (Plesiosauria, Elasmosauridae) from the Upper Cretaceous of Patagonia and Antarctica. Antarctic Science 25:71-82.

O'Gorman, J. P., S. Santillana, M. Reguero, and J. J. Moly. 2012. Primer registro de gastrolitos asociados a un espécimen de Aristonectes sp. (Plesiosauria, Elasmosauridae), Isla Seymour (Is. Marambio), Antártida; pp. 121-123 in M. Leppe, J. C. Aravena, and R. VillaMartínez (eds.), Abriendo Ventanas al Pasado, Libro de Resúmenes III Simposio-Paleontología en Chile. October 11-13, 2012, Punta Arenas, Chile.

O'Keefe, F. R. 2001. A cladistic analysis and taxonomic revision of the Plesiosauria (Reptilia: Sauropterygia). Acta Zoologica Fennica 213:1-63.

O'Keefe, F. R. 2002. The evolution of plesiosaur and pliosaur morphotypes in the Plesiosauria (Reptilia: Sauropterygia). Paleobiology 28:101-112.

O'Keefe, F. R., and N. Hiller. 2006. Morphologic and ontogenetic patterns in elasmosaur neck length, with comments on the utility of neck length variables. Paludicola 5:206-229.

O'Keefe, F. R., and H. P. Street. 2009. Osteology of the cryptocleidoid plesiosaur Tatenectes laramiensis, with comments on the taxonomic status of the Cimoliasauridae. Journal of Vertebrate Paleontology 29:48-57

O'Keefe, F. R., and W. Wahl. 2003. Current taxonomic status of the plesiosaur Pantosaurus striatus from the Upper Jurassic of Sundance Formation, Wyoming. Paludicola 4:37-46.

O'Keefe, F. R., H. P. Street, B. C. Wilhelm, C. D. Richards, and H. Zhu. 2011. A new skeleton of the cryptoclidid plesiosaur Tatenectes laramiensis reveals a novel body shape among plesiosaurs. Journal of Vertebrate Paleontology 31:330-33.

Olson, S. L. 1992. Neogaeornis wetzeli Lambrecht, a Cretaceous loon from Chile (Aves: Gaviidae). Journal of Vertebrate Paleontology 12:122-124.

Osborn, H. F. 1903. The reptilian subclasses Diapsida and Synapsida and the early history of the Diaptosauria. Memoirs of the American $\mathrm{Mu}-$ seum of Natural History 1:451-507.

Otero, R. A., and J. P. O'Gorman. 2013. Identification of the first postcranial skeleton of Aristonectes Cabrera (Plesiosauroidea, Elasmosauridae) from the upper Maastrichtian of the southeastern Pacific, based on a bivariate-graphic method. Cretaceous Research 41: 86-89.

Otero, R. A., S. Soto-Acuña, and D. Rubilar-Rogers. 2012. A postcranial skeleton of an elasmosaurid plesiosaur from the Maastrichtian of central Chile, with comments on the affinities of Late Cretaceous plesiosauroids from the Weddellian Biogeographic Province. Cretaceous Research 37:89-99.

Owen, R. 1860. On the orders of fossil and recent Reptilia and their distribution in time. Report of the British Association for the Advancement of Science 29:153-166.

Philippi, R. A. 1887. Los Fósiles Terciarios i Cuartarios de Chile. F.A Brockhaus, Leipzig, $236 \mathrm{pp}$.

Romer, A. S. 1956. Osteology of the Reptiles, University of Chicago Press, Chicago, Illinois, $772 \mathrm{pp}$.

Salazar, C., W. Stinnesbeck, and L.A. Quinzio-Sinn. 2010. Ammonites from the Maastrichtian (Upper Cretaceous) Quiriquina Formation in central Chile. Neues Jahrbuch für Geologie und Paläontologie Abhandlungen 257:181-236.

Sato, T. 2003. Terminonatator pointeixensis, a new elasmosaur (Reptilia; Sauropterygia) from the Upper Cretaceous of Saskatchewan. Journal of Vertebrate Paleontology 23:89-103.
Sato, T., Y. Hasegawa, and M. Manabe. 2006. A new elasmosaurid plesiosaur from the Upper Cretaceous of Fukushima, Japan. Palaeontology 49:467-484.

Steinmann, G., W. Deecke, and W. Möricke. 1895. Das Alter und die Fauna der Quiriquina-Schichten in Chile. Neues Jahrbuch für Mineralogie Geologie und Paleontologie 14:1-118.

Stinnesbeck, W. 1986. Zu den faunistischen und palökologischen Verhältnissen in der Quiriquina Formation (Maastrichtium) Zentral-Chiles. Palaeontographica, Abteilung A 194:99-237.

Stinnesbeck, W. 1996. Ammonite extinctions and environmental changes across the Cretaceous-Tertiary Boundary in Central Chile; pp. 289-302 in N. MacLeod and G. Keller (eds.), The CretaceousTertiary Boundary Mass Extinction: Biotic and Environmental Events. Norton Press, New York.

Stinnesbeck, W., C. Ifrim, and C. Salazar. 2012. The last Cretaceous ammonites in Latin America. Acta Paleontologica Polonica 57:717-728.

Suárez, M. E., and O. Fritis. 2002. Nuevo registro de Aristonectes sp. (Plesiosauroidea incertae sedis) del Cretácico Tardío de la Formación Quiriquina, Cocholgüe, Chile. Boletín de la Sociedad de Biología de Concepción 73:87-93.

Suárez, M. E., and R. A. Otero. 2009. Nuevos hallazgos de vertebrados marinos en el Campaniano-Maastrichtiano de Loanco, VII Región pp. 78-82 in A. Rubilar, D. Rubilar-Rogers, and C. Gutstein (eds.), I Simposio-Paleontología en Chile, Libro de Actas, October 2-3, 2008, Santiago, Chile.

Suárez, M. E., L. A. Quinzio, O. Fritis, and R. Bonilla. 2003. Aportes al conocimiento de los vertebrados marinos de la Formación Quiriquina; pp. 1-7 in Congreso Geológico Chileno No. 10, Resúmenes (CD-ROM), October 6-10, 2003, Concepción, Chile.

Vincent, P., N. Bardet, X. Pereda-Suberbiola, B. Bouya, M. Amaghzaz, and S. Meslouh. 2010. Zarafasaura oceanis, a new elasmosaurid (Reptilia: Sauropterygia) from the Maastrichtian phosphates of Morocco and the palaeobiogeography of latest Cretaceous plesiosaurs. Gondwana Research 19:1062-1073.

Welles, S. P. 1943. Elasmosaurid plesiosaurs with description of new material from California and Colorado. Memoirs of the University of California 13:125-254.

Welles, S. P. 1952. A review of the North American Cretaceous elasmosaurs. University of California Publications in Geological Sciences 29:47-144.

Welles, S. P. 1962. A new species of elasmosaur from the Aptian of Colombia and a review of the Cretaceous plesiosaurs. University of California, Publications in Geological Sciences 44:1-96.

Wetzel, W. 1930. Die Quiriquina-Schichten als Sediment und paläontologischen Archiv. Palaeontographica 73:49-106.

Wiffen, J., and W. Moisley. 1986. Late Cretaceous reptiles (families Elasmosauridae, Pliosauridae) from the Mangahouanga Stream, North Island, New Zealand. New Zealand Journal of Geology and Geophysics 29:205-252.

Zinsmeister, W. J. 1979. Biogeographic significance of the Late Mesozoic and early Tertiary molluscan faunas of Seymour Island (Antarctic Peninsula) to the final break-up of Gondwanaland; pp. 349-355 in J Gray and A. J. Boucot (eds.), Historical Biogeography, Plate Tectonics and the Changing Environment. Oregon State University Press, Corvallis, Oregon.

Submitted November 5, 2012; revisions received February 18, 2013; accepted February 24, 2013.

Handling editor: Randall Irmis. 


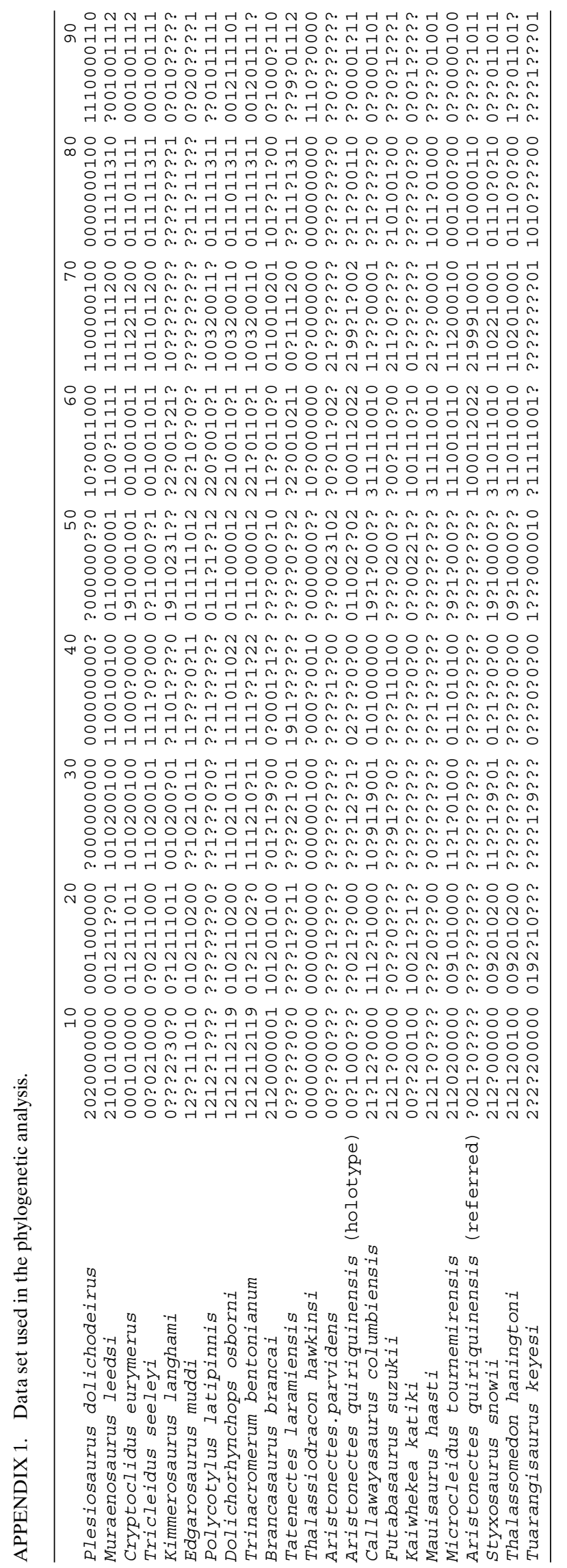

